\title{
Synergism of Pro-neurogenic miRNAs Provides a More Effective Strategy to Target Glioma Stem Cells
}

\section{Adam Kosti}

UTHSC at San Antonio: The University of Texas Health Science Center at San Antonio

\section{Rodrigo Barreiro}

UTHSC at San Antonio: The University of Texas Health Science Center at San Antonio

\section{Gabriela Guardia}

Hospital Sirio-Libanes

\section{Shiva Ostadrahimi}

UTHSC at San Antonio: The University of Texas Health Science Center at San Antonio

\section{Erzsebet Kokovay}

UTHSC at San Antonio: The University of Texas Health Science Center at San Antonio

\section{Alexander Pertsemlidis}

UTHSC at San Antonio: The University of Texas Health Science Center at San Antonio

\section{Pedro A.F. Galante}

Hospital Sirio-Libanes

Luiz Penalva ( $\sim$ penalva@uthscsa.edu )

Greehey Children's Cancer Research Institute, University of Texas Health Science Center at San Antonio, Texas https://orcid.org/0000-0003-4491-6769

\section{Research}

Keywords: miRNA, glioblastoma, neuroblastoma, miR-124, miR-128, miR-137

Posted Date: December 15th, 2020

DOI: https://doi.org/10.21203/rs.3.rs-125940/v1

License: (c) (i) This work is licensed under a Creative Commons Attribution 4.0 International License. Read Full License 


\section{Abstract}

Background: Tumor suppressor microRNAs (miRNAs) have been explored as agents to target cancer stem cells. Most strategies use a single miRNA mimic and present many disadvantages, such as the amount of reagent required and the diluted effect on target genes. miRNAs work in a cooperative fashion to regulate distinct biological processes and pathways. This information can be used to design more efficient ways to target cancer stem cells via miRNA combinations.

Methods: We transfected glioma stem cell and neuroblastoma lines with miRNA combinations and evaluate their impact on cancer relevant phenotypes and neuronal differentiation. RNA-seq analysis was conducted then to determine the expression alterations induced by the miRNA combination and map target genes and affected pathways.

Results: We have shown that miR-124, miR-128, and miR-137 function synergistically to regulate neurogenesis. We used a combination of these three miRNAs to treat glioma stem cells. miR-124, miR128 and miR-137 combined treatment was much more effective than single miRNAs in disrupting cell proliferation and survival and promoting differentiation and response to radiation. Transcriptomic analyses indicated that transcription regulation, angiogenesis, metabolism, and neuronal differentiation are among the main biological processes affected by transfection of this miRNA combination. Finally, in search of other combinations of other tumor suppressor/pro-neurogenic miRNAs, we identified a miRNA cluster based on target predictions and established miR-29, miR-101, and miR-218 combination as an alternative to be used in cancer therapy.

Conclusions: We demonstrated the value of using combinations of neurogenic miRNAs to disrupt cancer phenotypes and glioma stem cell growth. Our genomic analyses in GSCs established that the synergistic effect of these three miRNA amplified the repression of oncogenic factors and the effect on cancer relevant pathways. These results suggest that future therapeutic approaches would benefit from utilizing miRNA combinations, especially when targeting cancer-initiating cell populations.

\section{Introduction}

MicroRNAs (miRNAs) are small non-coding RNAs that act as essential post-transcriptional regulators [1] and are implicated in functions ranging from development to homeostasis [2]. miRNAs are especially important in cancers, where many have been identified as oncogenes or tumor suppressors [3]. Dysregulation of tumor-suppressive miRNAs is associated with the aggressive and undifferentiated nature of neural-derived cancers. [4, 5]. GBM and neuroblastoma arise from transformed neural precursors [6, 7], where normal stem cell programs are taken over. Therefore, the use of pro-neurogenic miRNAs as agents to induce terminal differentiation and turn off oncogenic pathways has been proposed as an option to treat these tumors [8]. In the brain, miRNAs control processes such as neuronal differentiation, neuronal processes, and regional specialization [9]. Marked changes in miRNA profiling have been observed during neurogenesis and in comparisons between undifferentiated and differentiated 
cells [10]. Among brain enriched miRNAs, miR-124-3p, miR-128-3p, and miR-137-3p (hereinafter miR-124, miR-128, and miR-137) stand out. Decreased expression of these three tumor suppressor miRs occur in different cancers $[11,12]$. miR-124 is known for its high abundance, accounting for most miRNAs in a neuron [8] and plays roles in CNS development, neurodegeneration, CNS stress, stroke, and neuroimmunity [13]. miR-128 has been connected to Huntington's disease [14] and associated with anxiety disorders [15]. miR-128 increases expression during brain development, leading to repression of nonsense mediated decay machinery and upregulation of mRNAs normally targeted for decay. miR-137 is a well-characterized marker of schizophrenia susceptibility [16] and is downregulated in brain tissue from patients with depression and suicidal behavior [17].

We have previously shown that miR-124, miR-128, and miR-137 have similar patterns of expression during neurogenesis. When combined, these three miRNAs have a much stronger effect on differentiation and proliferation, suggesting that they act synergistically to coordinate adult neuronal differentiation [18]. This synergistic effect can be explained based on their target sets, which are highly overlapping and also connected via networks of associated genes, with transcription factors forming important regulatory interactions [18]. In cancer, downregulation of these three miRNAs contributes to the acquisition of a less differentiated phenotype. Multiple studies in different tumor types have shown that transfection of mimics of these three miRNAs affects several cancer-relevant phenotypes and block tumor growth [11, $19,20]$.

Most pre-clinical and clinical studies using miRNA mimics or antagomiRs as therapeutic agents are designed around a single miRNA [21]. This approach poses many limitations, including the amount of agent required to have a therapeutic effect and reduced regulatory impact on target genes. As in the example of miR-124, miR-128, and miR-137, many other miRNAs work cooperatively or synergistically to regulate critical biological processes [22]. Taking advantage of these regulatory interactions, there is growing interest in the concept of using miRNA combinations in cancer therapy [23]. In this study, we show that the combination of miR-124, miR-128, and miR-137 works more effectively than single miRNA. Genomic analyses established that this miRNA combination downregulated target genes implicated preferentially in transcription regulation, metabolism, neuronal differentiation, and angiogenesis. Finally, we show that miR-124, miR-128, and miR-137 belong to a larger network of pro-neurogenic tumor suppressor miRNAs; thus, other miRNA combinations also could be effective in targeting cancer cells, expanding treatment options.

\section{Materials And Methods}

\section{Glioblastoma and neuroblastoma cell culture and transfections}

Glioblastoma U251 and U343 cells were obtained from the University of Uppsala (Sweden) and cultured in Dulbecco's modified Eagle's medium supplemented with $10 \%$ fetal bovine serum, $100 \mathrm{U} / \mathrm{ml}$ penicillin, and $100 \mathrm{\mu g} / \mathrm{ml}$ streptomycin. Cells were maintained at $37^{\circ} \mathrm{C}$ in a $5 \% \mathrm{CO}_{2}$ atmosphere. Neuroblastoma $\mathrm{BE}(2) \mathrm{C}$ were obtained from the American Type Culture Collection and Kelly cells were obtained from the 
Cancer Therapy and Research Center, San Antonio, TX. Neuroblastoma cells were grown in DMEM/F-12 supplemented with $10 \%$ fetal bovine serum, $100 \mathrm{U} / \mathrm{ml}$ penicillin, and $100 \mu \mathrm{g} / \mathrm{ml}$ streptomycin. Glioma stem cell (GSC) lines (Mesenchymal: 3565, 3128, 1123NS and Proneural: 1919, 19NS, 84NS) were gifts from Drs. Jeremy Rich, Christopher Hubert, and Ichiro Nakano [24, 25]. GSCs were cultured in serum-free media consisting of Neurobasal-A media supplemented with B-27, sodium pyruvate, Glutamax, penicillin/streptomycin, $20 \mathrm{ng} / \mathrm{ml}$ EGF (ThermoFisher), and $20 \mathrm{ng} / \mathrm{ml} \mathrm{hFGF} \mathrm{(PeproTech).} \mathrm{Every} 72$ hours, GSCs were pulsed with EGF/FGF. Dissociation was performed by incubating GSCs with Accutase (ThermoFisher) at room temperature for 10 minutes.

miRNA mimics were obtained from Qiagen (Negative Control Mimic: YM00479903, miR-124: YM00471256, miR-128: YM00471226, miR-137: YM00472450, miR-29a-5p: YM00470481, miR-218-5p: YM00471984, miR-101-5p: YM00470928), and were used in the experiments as described below.

\section{Proliferation assays}

Glioblastoma and neuroblastoma cells were reverse-transfected with control or miRNA mimics into 96well plates at densities ranging from $0.8-5 \times 10^{3}$. Growth curves were generated by an automated and non-invasive Incucyte ${ }^{\circledR}$ system live cell imaging system (Essen BioSciences). Cells were imaged every 48 hours. All experiments were performed with three biological and technical replicates.

\section{Differentiation assays}

Neuroblastoma cells were reverse-transfected with control or miRNA mimics into 96-well plates at a density of $2.5-5 \times 10^{3}$. Cells were cultured for 120 hours and were imaged with the Incucyte ${ }^{\circledR}$ system live cell imaging system. Differentiation was assessed by total neurite length using IncuCyte ${ }^{\circledR}$ NeuroTrack Software Module (Essen BioSciences). All experiments were performed with three biological and technical replicates.

\section{MTS assays}

For cell viability assays, $10^{3}$ cells per well were plated in a 96-well plate and reverse- transfected with control or miRNA mimics. 96 hours after transfection, cell viability was measured using CellTiter-Glo (Promega) following the manufacturer's instructions. For GSC lines, cells were dissociated and reversetransfected at a density of $10^{4}$ cells/well with miRNA control or miRNA mimics and plated into 96-well plates precoated 3 hours prior with Geltrex ${ }^{\text {TM }}$ LDEV-Free Reduced Growth Factor Basement Membrane Matrix (19.2-28.8 mg/ml). Absorbance was quantified at $490 \mathrm{~nm}$. All experiments were performed with technical triplicates.

\section{Colony formation assays}

U251 or U343 cells were reverse-transfected with control or miRNA mimics. 24 hours later, cells were trypsinized and re-plated at a density of 0.2 cells/ $\mu$ l. Cells were kept in culture for $10-14$ days until colonies were clearly visible. Colonies were fixed with $4 \%$ paraformaldehyde solution and visualized by 
staining with $1 \%$ crystal violet. Crystal violet was dissolved from stained plates and absorbance was measured with at $570 \mathrm{~nm}$. All experiments were performed with technical triplicates.

\section{Response to radiation}

U251 or U343 cells were reverse-transfected with control or miRNA mimics. 24 hours later, cells were trypsinized and exposed to varying doses of ionizing radiation, using a CP-160 Cabinet X-Radiator (Faxitron X-Ray Corp). Cells were then re-plated, either for MTS assays to assess viability or plated for clonogenic potential. MTS assays were performed as described earlier. Two weeks after irradiation, clonogenic potential was assessed as described earlier. All experiments were performed in triplicate.

\section{Traffic light reporter assays}

Traffic Light Reporter (Addgene: 31481) and d20GFP-Donor (Addgene: 31485) plasmids were used to generate lentiviral particles. Lentiviruses were generated and titered as previously described [26]. Traffic light reporter assays were performed as previously described with minor modifications [27]. U343 and U251 cells were first infected with an $\mathrm{MOI}$ of 13.96 hours later, cells were replated into 96 -well plates at a density of $10^{4}$. Cells were co-transfected with $100 \mathrm{ng}$ of I-Scel plasmid along with either $50 \mathrm{nM}$ of control or miRNA mimics using Lipofectamine 3000.72 hours after transfection, whole wells were imaged with a Celigo automated cell imager (Nexcelom Bioscience). Total numbers of GFP and RFP positive cells were counted and used to calculate the HDR:mutNHEJ Ratio. The I-Scel plasmid was a kind gift from Dr. Alexander JR Bishop. Experiments were performed in triplicates.

\section{miRNA correlation and survival analysis in patients}

MiRNA expression and survival data for the TCGA LGG cohort were obtained from UCSC Xena (http://xena.ucsc.edu) [28]. TCGA GBM data were obtained from (https://gdc.cancer.gov/aboutdata/publications/gbm_2013) [29]. MiRNA and survival data for the neuroblastoma cohort were obtained from the study of Schulte et al. [30]. GBM survival data were obtained from the study by D'Urso et al. (GEO: GSE13030) [31]. Correlation was assessed by Pearson's correlation coefficient. For survival analysis, miRNA expression was normalized by z-score and the resulting average z-score for each patient was used for log-rank and Kaplan-Meier analysis.

\section{Statistical analysis - Biological Assays}

Statistical significance of differences in proliferation and differentiation at the 120-hour endpoint were determined by a one-way ANOVA with a post-hoc Tukey test for multiple comparisons. Synergy combination indices were calculated using: 1) Linear interaction model $\left.\mathrm{Cl}=\left(E_{\mathrm{A}}+E_{\mathrm{B}}+E_{\mathrm{C}}\right) / E_{\mathrm{ABC}} ; 2\right)$ Bliss independence model $\mathrm{Cl}=\left(\left(E_{\mathrm{A}}+E_{\mathrm{B}}+E_{\mathrm{C}}\right)-\left(E_{\mathrm{A}} E_{\mathrm{B}} E_{\mathrm{C}}\right)\right) / E_{\mathrm{ABC}}$. MTS and clonogenic assays were analyzed by oneway ANOVA and a post-hoc Tukey test for multiple comparisons. For radiation experiments, a two-way ANOVA with a post-hoc Tukey test for multiple comparisons was used. Results from the traffic light reporter assays were analyzed with Student's t-tests. 


\section{miR-124, miR-128 and miR-137 target compilation}

miR-124, miR-128, and miR-137 targets were compiled from our previous studies [18]. We also included target genes of the three miRNAs obtained from mirTarBase [32] for which there was strong experimental evidence.

\section{RNA extraction and RNA-Seq analysis}

$\mathrm{BE}(2) \mathrm{C}, 3565$, and 1919 cells were reverse-transfected in technical triplicates with $30 \mathrm{nM}$ of miRNA mimics (control vs. miR-124/miR-128/miR-137 combination). 48 hours later, total RNA from transfected cells was extracted using TRIzol reagent (Thermo Fisher) according to the manufacturer's instructions. RNA was purified and concentrated utilizing RNA Clean \& Concentrator-5 kit (Zymo Research). Libraries for RNA sequencing were prepared using TruSeq RNA Library Prep Kit v2 (Illumina), following the manufacturer's instructions, and sequenced at the GCCRI Genome Sequencing Facility on a HiSeq-3000 sequencer (Illumina). Three biological replicates of control and experimental samples were used in each study.

Data were deposited in European Nucleotide Archive (ENA, www.ebi.ac.uk/ena) with the study identifier PRJEB40058.

\section{Transcriptomic analyses}

Transcript quantification was performed using Kallisto (v0.43.1, parameters: -bootstrap-samples=100 single -II 350 -s 10)[33] with insert metrics obtained from the library construction. Gene-level counts were obtained using the R package tximport v1.0.3 [34]. GENCODE v29 (gencodegenes.org) was used as the reference for the human transcriptome. Differential gene expression analyses were carried out with DESeq2 v3.6.2 [35]. Genes were classified as differentially expressed using adjusted $p$-values $<0.05$ and |log2FoldChangel $\geq 0.5$.

Two main gene lists containing the overlap of the three different studies were generated. The upregulated gene set consists of the genes considered up-regulated after transfection of the miRNA combination in at least two studies. The same strategy was used to generate the downregulated gene set. For both sets, only protein coding genes were included and conflicting expression behavior genes (i.e. genes downregulated in one comparison and upregulated in another) were removed from the lists.

\section{Correlations between binding sites and gene silencing}

To assess correlations between silencing and presence or absence of binding sites for each of the three miRNAs, log2FoldChange of down-regulated genes and not differentially expressed genes were analyzed accordingly with the number of miRNAs targeting the gene. Wilcoxon tests to analyze differences between the group without miRNA targeting and with at least one target were performed for each cell line. 
To evaluate correlations between silencing and the number of binding sites, each gene down-regulated in at least two of three studies was assigned with a total amount of miR-124,-138, and -137 binding sites indiscriminately. Binding site data were retrieved from TargetScan [36]. Genes were classified between high and low silencing according to the 1 st and 3rd quartile. Genes with Log2FoldChange's standard deviation greater than 0.5 between studies were removed from the analysis. Wilcoxon tests were used to assess differences between the high silencing and low silencing groups. Data were further categorized as being in a single site or multiple sites and statistical differences between groups were assessed by Chisquared tests.

\section{Permutation analyses}

To determine if the down-regulated sets contain more targets of miR-124, miR-128, and miR-137 than expected by chance, we performed a permutation test with 10,000 iterations. Random samples of the same size as the down-regulated sets in all three cell lines $(n=253)$ were extracted from all differentially expressed genes. Next, the percentage of genes targeted by 2 or more miRNA in the sample was calculated.

\section{LncRNA analyses}

To identify potential interactions between miR-124, miR-128, miR-137, and IncRNAs, a list with the IncRNA down-regulated in at least two cell lines was collected. Sequences of IncRNAs were obtained from LNCipedia v5.2 [37]. Binding site prediction for these IncRNAs was performed using miRmate [38]. For further analyses, we created a list of IncRNAs that contained predicted miRNA binding sites for all three miRNAs.

\section{Gene Ontology analyses}

Gene Ontology (GO) enrichment analysis was performed with the PANTHER statistical overrepresentation test webtool [39]. For all analyses, the whole human genome was used as background. For a summarized GO term selection, PANTHER's term list was inputted to REVIGO [40] and the output table was sorted by uniqueness and dispensability. KEGG pathway enrichment analysis was performed using the ShinyGO web tool [41]. In both analyses, terms and pathways with FDR-adjusted $p$-values $<0.05$ were considered enriched.

\section{Transcription Factor and network analysis}

A list with transcription factors was obtained from Lambert et al. [42] and the network was generated with Cytoscape software [43] using STRING's protein-protein interaction data [44] (minimum interaction score of 0.7$)$.

\section{Expression of miRNA targets in neuroblastoma and glioblastoma samples}


Expression levels of identified miRNA targets in neuroblastoma samples were investigated. Stage 1 and Stage 4 neuroblastoma expression data were obtained from R2 (r2platform.com). The dataset from Kocak et al. contains microarray data from 266 patients (118 Stage 1 and 148 Stage 4)[45]. Following the procedures available in the R2 differential expression webtool, p-values were generated by ANOVA tests between log2 transformed data. Genes were considered differentially expressed if $p$-values (adjusted for false-discovery rates [FDR]) were below 0.01 .

Mapped RNA sequencing data from 154 primary glioblastoma (GBM) and 248 primary glioma grade II (LGG) samples were obtained from The Cancer Genome Atlas Program (TCGA). TCGA datasets were first reprocessed using Kallisto [33] with GENCODE v29 (gencodegenes.org) as the reference for the human transcriptome. Gene-level counts were also obtained using Tximport v1.0.3 [34]. Gene-level counts from 465 healthy (frontal) cortex samples were directly obtained from the Genotype-Tissue Expression - GTEx portal v8 (gtexportal.org). Analyses of differential gene expression were performed between glioblastoma and glioma grade II samples, as well as between glioblastoma and healthy cortex samples using the $\mathrm{R}$ package DESeq2 [35]. Only genes presenting a |log2FoldChangel $\geq 1$ and FDR-adjusted $p$-values $<0.05$ were considered differentially expressed.

\section{miRNA in silico cluster identification}

Target predictions for all broadly conserved miRNA families were first obtained from Targetscan [46]. We selected miRNA families with at least 1,000 predicted targets and generated a list of targets shared by at least two of the selected miRNAs. Finally, the selected miRNA families were hierarchically clustered based on information of their shared targets. The miRNA list was further filtered after a literature search for potential roles in glioblastoma and neuroblastoma. We included additional miRNAs sharing a large number of targets with miRNAs in the cluster. The final dataset contains targets of 11 miRNA (miR-1013p.2, miR-124-3p.1, miR-128-3p, miR-137, miR-181-5p, miR-218-5p, miR-26-5p, miR-29-3p, miR-144-3p, miR-153, miR-543) collected from TargetScan. Hierarchical clustering was carried out in R by pvclust package v2.2 [47] using Euclidean distance and Ward's hierarchical clustering method.

\section{Results}

\section{Establishing miRNA synergism as a tool for therapy}

We have previously shown that miR-124, miR-128 and miR-137 share a large set of target genes and work synergistically to promote neuronal differentiation (Fig. 1, Table 1) [18]. Moreover, their expression patterns during neurogenesis and in healthy brain tissue suggest that they are co-expressed and coregulated [18]. Similarly, analyses of TCGA LGG, GBM, and neuroblastoma miRNA profiling studies showed that these three miRNAs display strong correlations of expression (Fig. 2A) [30]. Agreeing with their role as tumor suppressors, higher overall expression of these three miRNAs based on z-score average was associated with better prognosis (Fig. 2B) [31]. 
miR-124, -128 , and -137 individually display anti-tumorigenic activity [11, 12]. Capitalizing on our previous findings, we examined whether the combination of the three miRNAs was more effective in targeting cancer cells than single miRNAs. Based on observed associations between these three miRNAs, we expected they would have a stronger impact on shared targets and robust repression of critical pathways based on the functional relationship of their target sets (Fig 1). We first tested their functional synergy in GBM cell lines using the response additivity model (or linear interaction effect) [48]. Low doses of each miRNA individually produced no significant changes in proliferation; however, when the three low doses were combined, they significantly inhibited proliferation based on live-cell imaging, indicating synergy with a combination index $(\mathrm{Cl})$ of 0.339 (Fig. 3A and E). Using a more common model, the Bliss independence model [48], the selected miRNAs also strongly synergized, with $\mathrm{Cl}$ of 0.338 for $\mathrm{U} 251$ and 0.151 for U343 at 120 hours. Next, we transfected GBM cells with the same equimolar amount of miRNA mimics (single miRNA and miRNA combination) and tested whether effects of the miRNA combination vs. single miRNA mimics on GBM cells supported our model of synergism. In both GBM lines, the miRNA combination decreased proliferation more significantly than any single miRNA at the same dose (Fig 3B and F). In addition, the combination inhibited glioma cell viability (Fig. $\mathbf{3 C}$ and $\mathbf{G}$ ) and clonogenic potential (Fig. 3D and $\mathrm{H}$ ) more significantly than any miRNA by itself.

Recurrence is the most frequent cause of GBM mortality [49]. Tumor-initiating cells or GSCs evade initial treatments and result in recurrence, making them an important cell population to target [50]. Previously, the three miRNAs had been explored individually as tumor suppressors in GSC cultures [11, 12]; however, it was unknown whether they would synergize as seen in the GBM cell lines (Fig. 3). We tested the efficacy of the miRNA combination in six GSCs with two distinct molecular subtypes (mesenchymal and proneural). Using the same total molecular amount, we observed in all six lines that miRNA combination had a stronger impact on cell viability than individual miRNAs and induced morphologic changes (Fig. 4).

The miRNA combination also displayed significant effects on the proliferation of neuroblastoma $\mathrm{BE}(2) \mathrm{C}$ and Kelly cells. The combination demonstrated synergy based on the response additivity model $\mathrm{Cl}$ of 0.355 and 0.264 for each cell line, respectively (Fig. S1A). A hallmark of neuroblastoma cells is their ability to differentiate into benign neuron-like cells with long neurites and small cell bodies [51]. Differentiation agents like retinoic acid are often used to treat high-risk neuroblastoma [52]. We used a morphologic assay to assess differentiation [53]; and found that the miRNA combination was more effective than individual miRNAs in driving neuroblastoma cell differentiation, based on increases in neurite length (Fig. S1B-C).

\section{Combined impact of miR-124, -128 and -137 on gene expression}

To understand the effects of combined miR-124, miR-128 and miR-137 mimics on gene expression, we performed RNA-seq in mesenchymal and proneural GSCs and neuroblastoma BE(2)C cells. Detailed results are provided in Tables S2 and S3. In the down-regulated sets, 757 genes appeared in at least two out of the three studies (Fig. 5A). Based on our miRNA target list (Table S1), we determined that the percentage of genes containing binding sites for at least one of the three selected miRNAs was much 
higher in the overlap set compared to the gene set downregulated in a single cell line (Fig. 5A). Of the 757 genes, 392 contained binding sites for at least one of the transfected miRNAs. The proportion of targets of miR-124/128/137 in the overlap was also higher than in the up-regulated set and what would be expected by chance according to a permutation analysis (Fig. 5A-B). We also observed more genes containing binding sites for two or three of the transfected miRNAs in the overlap compared to the gene set downregulated in a single cell line (Fig. 5C). Supporting our definition of synergism, we observed that genes targeted by all three miRNAs tended to have greater changes in expression than genes targeted by two or a single miRNA. Results were similar in all three individual analyses (Fig. 5D).

We next explored the biological nature of the 392 miRNA targets present in the overlap of our analyses. Since miR-124, miR-128, and miR-137 are tumor suppressor miRNAs and tend to be downregulated in tumors, we expected that their targets would show the opposite behavior. In GBM and neuroblastoma datasets, the miRNA targets present in all three analyses showed increased expression in GBM than in normal brain and higher expression in stage IV than in stage I neuroblastoma compared to miRNA targets present in two or in a single analysis (Fig. 5E, Table S4).

We examined biological processes and pathways preferentially associated with the miRNA target genes present in the overlap. Among the GO categories that appeared more often were those associated with development, neuronal differentiation, transcription regulation, and metabolism (Fig. 6A, Tables S4 and S5). In a previous analysis to evaluate the individual impact of miR-124, miR-128, and miR-137 on neurogenesis, we determined that an important component of their programs consists of inhibition of transcription factors [18]. Network analysis showed that transcription regulation and neuronal differentiation are strongly associated, and many transcription factors were identified as main nodes of the identified network. Among the most relevant ones are three transcription factors with known oncogenic roles - MYB, TCF12, and TCF3 (Fig. 6B). Other oncogenic factors were identified as targets of miR-124, miR-128, and miR-137 in the genomic analysis (Fig. 6C). Agreeing with the proposed idea that associated miRNAs can be more effective in targeting a particular biological process or pathway by expanding the number of affected genes, we observed that the described network contains a combination of targets of individual miRNAs, as well as genes targeted by two or three miRNAs (Fig. S2).

To identify further associations between identified target genes and other biological processes affected by the miRNA combination, we conducted an analysis with HumanBase [54]. Three main functional modules were identified. In Module 1, main terms were related to histone modification and DNA repair; Module 2 was strongly linked to angiogenesis; and in Module 3, among the main terms were transforming growth factor beta and formation of ribonucleoprotein complex- (Fig. S3 and Table S6).

Genes showing increased expression after transfection of the miRNA combination are preferentially associated with protein kinase activity, protein localization and secretion, and cell morphogenesis (Fig S5 and Table S5).

\section{Radio-sensitization by miRNA combination}


Radiotherapy is a cornerstone of GBM treatment, along with surgical resection and chemotherapy [49]. Radioresistance is a major cause of recurrence in GBM. GSCs are notoriously radioresistant, and sensitizing them to ionizing radiation is critical for therapy. Alterations in DNA damage repair pathways enable GSCs to escape lethal damage [55]. Homologous recombination is particularly important in radioresistance of GSCs, allowing them to repair severe damage caused by therapy [56]. A large number of genes implicated in DNA repair, DNA replication, and cell cycle were altered upon miRNA combination transfection based on the RNA-seq analysis (Tables S5 and S6). This could potentially skew the DNA repair pathways that GBM cells normally rely upon and make them more sensitive to treatment with ionizing radiation. We also observed that $\mathrm{U} 251$ and $\mathrm{U} 343$ cells transfected with $25 \mathrm{nM}$ of the miRNA combination further disrupted the clonogenic ability of these cells and decreased their viability. To better illustrate effects of miRNA combination, we normalized values to the respective non-irradiated controls and present the results for control vs. combination transfected cells side by side (Fig. 3l, J, L and M).

Next, to assess if the miRNA combination altered DNA repair pathways in GBM cells, we used a traffic light reporter assay that indicates the ratio of homologous recombination to mutant prone nonhomologous end joining [27]. The miRNA combination significantly decreased the rate of homologous recombination, suggesting that enhanced radiosensitization by the miRNA combination is due to targeting DNA repair pathways (Fig $3 \mathrm{~K}$ and $\mathrm{N}$ ).

\section{IncRNA expression is affected by miRNA combination}

We identified several downregulated IncRNAs in the overlap of three analyses. We then used our target prediction tool [38] to determine which ones contain putative miRNA binding sites for miR-124, -128, and -137 (Table S3). Among the ones potentially targeted by all three miRNAs, we identified NEAT1, MALAT1, FAM95B1, and AC048341.1 (Fig. S4A). NEAT1 and MALAT1 are well characterized IncRNAs and have been implicated in tumor progression, including GBM $[57,58]$. MALAT1 has been linked to temozolomide resistance in GBM [59]. NEAT1 functions as a sponge for several tumor suppressor miRNAs in glioblastoma [60, 61] and influences critical pathways such as Wnt [62]. High NEAT1 expression correlates with larger tumor size, higher WHO grade, prognosis and recurrence [63]. We have shown that NEAT1 expression increases after GBM cells are exposed to radiation [64]. Although, FAM95B1 is still a poorly characterized IncRNA, one study in papillary thyroid carcinoma showed that FAM95B1 is significantly correlated with cervical lymph node metastasis, tumor staging and prognosis [65]. FAM95B1 shows higher expression in glioblastoma (TCGA-GBM) compared with normal cortex samples from GTEx and lower-grade glioma (TCGA-LGG). Survival analysis using patient data from TCGA and CCGA available in GlioVis [66] showed that FAM95B1 high expression is linked to poor glioma patient survival (Fig. S4B-C).

\section{Establishing other examples of miRNA synergism}

Cooperation or synergism between miRNAs has been observed in other systems and scenarios [67]. To identify other miRNA combinations that also could be explored as potential therapies, we looked for examples of tumor suppressor miRNAs sharing a large number of targets. Using all Targetscan 
predictions [36] for conserved miRNA families, we identified an initial group that included miR-124, miR128 , and miR-137 and shared strong similarity in their target sets. We eliminated from this list miRNAs that do not work as tumor suppressors and included others from non-conserved families that share many targets with the initial group and are relevant to GBM and/or neuroblastoma development. The final list includes 11 miRNAs - Fig. 7A-B and Table S7. We performed GO and pathway analyses, focusing on genes predicted to be targeted by at least 5 miRNAs from the identified group. Similar to the RNA-seq study described above, we found that this group of genes is strongly associated with neuronal differentiation, nervous system development and transcription regulation (Fig. 7C).

To demonstrate that other miRNA combinations could be explored as potential therapies, we selected miR-29a, miR-101, and miR-218 for analysis. These three miRNAs show the same level of target similarity as miR-124, miR-128, and miR-137 and display increased expression during neuronal differentiation. All three have been implicated in GBM and/or neuroblastoma development (Table S7). As before, we determined the impact of individual and combined miRNA transfections on cell proliferation and differentiation, using the same final molecular amount. The miRNA combination produced a stronger impact on proliferation of U251, BE(2)C cells and GSCs 1123 NS and 84NS and more effectively promoted differentiation of $\mathrm{BE}(2) \mathrm{C}$ cells (Fig. 7D). Based on both the response additivity and Bliss independence models, the three new miRNAs synergized with $\mathrm{Cl}$ of 0.731 and 0.443 for $\mathrm{U} 251$ and BE(2)C, respectively.

\section{Discussion}

\section{miRNA combination as a more robust approach for cancer therapy}

Only a few miRNA-based therapies have progressed to clinical trials. Typical issues include the low magnitude of the suppressive effect [68] and the fact that high amounts of miRNA are responsible for a series of off-target effects [69]. Thus, the use of cooperative or synergistic miRNAs can represent a solution, since the combined use of these miRNAs at lower doses could reduce off-target effects, while their synergistic or combinatory effects could provide enough gene-level or network-level suppression to result in a better therapeutic outcome $[23,67,70]$.

We have previously shown that miR-124, miR-128, and miR-137 act synergistically in neurogenesis by targeting a group of common and associated target genes [18]. Moreover, when combined, these three miRNAs produced a much stronger repression of common targets such as SP1 [18]. Cooperation between multiple miRNAs is tied to an array of important cellular processes, such as cell cycle, apoptosis, and differentiation, and their concomitant dysregulation have been linked to disease development [71]. In the setting of cancer, examples of miRNA synergism have been emerging. For instance, miR-34a and miR$15 a / 16$, both tumor suppressors, are often down-regulated in the same tumor tissues. In non-small cell lung cancer, miR-34a and miR-15a/16 mimics produced a synergistic effect and induced cell cycle arrest in a Rb-dependent manner [72]. In pediatric acute lymphoblastic leukemia, the combination of miR-125b, miR-100, and miR-99a was more effective in inhibiting target genes associated with chemoresistance than single miRNAs [73]. Similarly, miR-205 and miR-342 increased sensitivity of melanoma and lung 
cancer cells to a genotoxic cancer drug [74]. On the other hand, miRNA synergism can contribute to tumor development; simultaneous inhibition of the onco-miRs miR-21, miR-23, and miR-27a reduced proliferation of pancreatic ductal adenocarcinoma in vitro and decreased tumor growth more effectively then inhibition of a single miRNAs [75]. In gliomas, simultaneous inhibition of miR-21 and miR-10b sensitized tumor cells in vitro and in vivo to a lower dose of temozolomide [76].

\section{miR-124, miR-128, and miR-137 target genes in differentiation and development}

We and others have previously shown in individual target analyses of miR-124, miR-128, and miR-137 that these three miRNAs activate programs implicated in differentiation while repressing signals that promote stemness $[18,20]$. Therefore, we expected the miRNA combination to direct GBM and neuroblastoma cells towards differentiation and to impact the viability of cancer stem cells. The RNA-seq analysis identified multiple target genes implicated in neuronal differentiation and nervous system development. Among them were several oncogenic factors, including AKT2, CDH11, TTL, GATA2, NFIB, SUZ12, CDC42, EGFR, and SRC. The last three are the main nodes of the identified network. CDC42 is a small GTPase of the Rho subfamily and has been implicated in cell morphology, cell migration, endocytosis, and cell cycle progression [77]. Knockdown or inhibition of CDC42 in GBM and neuroblastoma cells decreases proliferation and invasion, while increasing chemosensitivity [78, 79]. SRC and EGFR are members of the ErbB signaling pathway, which we observed to be enriched in the KEGG pathway analysis. This pathway is activated in numerous tumor types, including GBM and neuroblastoma, with several of its genes often displaying increased expression [80, 81]. Targeting ErbB signaling pathway members has been explored as a therapeutic option [82]. KEGG pathway analysis also identified several miRNA target genes regulating pluripotency of stem cells (e.g., MAPK14, DVL2 AKT2, ID3, SMAD5, SMAD9, BMI1, SKIL, TCF3, and PCGF6). Finally, mapping of functional modules identified genes associated with histone and chromatin modification (TAF12, UBE2N, PCGF6, DR1, KDM1A, YEATS4, MYB, PHB, and SUZ12). Epigenetic regulation plays an important role in driving gene signatures implicated in stem cell identity and neuronal differentiation [83].

\section{Combination of miR-124, miR-128 and miR-137 targets a transcription factor network}

miRNAs and transcription factors concomitantly modulate expression of many target genes and act as central nodes of gene networks, such as those implicated in the origin and progression of neuroblastoma and gliomas $[84,85]$. Associations between transcription factors and miRNAs are very common in biology and have been described in different systems. For instance, TF-miRNA circuits were well defined and shown to be critical components of $C$. elegans development [86]. Other important examples were characterized in the context of the nervous system [87]. These two kinds of regulatory molecules (miRNAs and TFs) can work together in networks to produce large-scale expression changes in cancer. For instance, miRNA-TF modules have been identified in breast cancer and glioblastoma through computational analyses of genomic datasets [88].

Our previous analysis determined that miR-124, miR-128, and miR-137 regulate numerous transcription factors in the context of neurogenesis [18]. SP1, which was also identified as a target in the present study, 
appeared as the central node of the identified TF network. SP1 has been implicated in glioblastoma and neuroblastoma development $[89,90]$ and is regulated by all three miRNAs synergistically [18]. Besides SP1, several other oncogenic transcription factors linked to neuronal differentiation, such as MYB, PPARG, TCF3, and TCF12, were identified as miRNA targets down-regulated by the combination. MYB or C-MYB belongs to a large family of transcription factors containing HTH DNA-binding domains. MYB regulates the neuroblastoma oncogene $\mathrm{MYCN}$, by controlling its expression and amplification in neuroblastoma lines [91]. In glioblastoma, MYB is an effector of the ZEB-1 pathway, which is implicated in epithelial-mesenchymal transition and key features of cancer stem cells [92]. TCF3 and TCF12 are members of the basic helix-loop-helix (bHLH) E-protein family that recognizes the consensus binding site (E-box) sequence. TCF3 knockdown in GBM cells induced apoptosis and inhibited cell migration via Akt and Erk pathway inhibition [93]. In neuroblastoma, TCF3 shows increased expression in MYCN amplified tumors, and its increased expression is linked to poor prognosis [94]. TCF12 ectopic expression in the hippocampus of young rats led to significant deficits in spatial working memory. Moreover, several Tcf12 rats developed tumors similar to glioblastomas [95]. On the other hand, TCF12 knockdown reduced proliferation and neurosphere formation and altered cell cycle distribution of GBM cells [96].

\section{Conclusion}

We still know very little regarding mechanisms implicated in miRNA cooperativity or synergism and the functional outcome of these interactions. miRNA cooperation or synergism impacts multiple biological processes including stem cell fate decisions. Several groups have used system biology approaches to integrate multiple layers of genomic information and identify such interactions $[23,67,71,97,98]$.

We show here that miR-124, miR-128 and miR-137 can synergize to disrupt cancer-relevant phenotypes and GSC growth and that other combinations of tumor suppressive/pro-neurogenic miRNAs could also produce a similar effect. An ideal platform to move this concept into the clinic would require a systems approach to identify optimal miRNA combinations and tumor matches based on expression profile and clinical data. However, as exemplified by our study, functional validation and genomic analyses are necessary steps to establish the potential therapeutic use of a miRNA combination.

\section{List Of Abbreviations}

miRNAs: microRNAs

GBM: glioblastoma multiforme

GSC: glioma stem cell

IncRNAs: Long non-coding RNAs

bHLH: helix-loop-helix 
ANOVA: Analysis of variance

Cl: Combination Index

TF: Transcription factor

HTH: Helix-turn-helix

HDR: Homologous recombination

mutNHEJ: Mutant non-homologous end joining

\section{Declarations}

\section{Ethics approval and consent to participate}

Not applicable.

\section{Consent for publication}

Not Applicable.

\section{Competing interests}

The authors declare that they have no competing interests.

\section{Data availability}

Datasets for this work can be found at the European Nucleotide Archive (ENA, www.ebi.ac.uk/ena) with the study identifier PRJEB40058 or in the Supplementary Tables. Additional data can be obtained upon reader's request.

\section{Funding}

This work was sponsored by the Owens Foundation and 1 R21 NS113344-01A1 (NINDS/NIH) to LOFP and EK. RNA-seq data were generated at the Genome Sequencing Facility which is supported by UT Health San Antonio, NIH-NCI P30 CA054174 (Mays Cancer Center, UT Health San Antonio), NIH Shared Instrument grant 1S100D021805-01, and CPRIT Core Facility Award (RP160732). AK was supported by 2R01 HG006015S1 and the Greehey Foundation. RB was sponsored by the Coordenação de Aperfeiçoamento de Pessoal de Nível Superior - Brazil (Capes) - Finance Code 001.

\section{Authors Contributions}

AK-Performed most of the biological assays, contributed to experimental design, manuscript writing and figure preparation. 
RB - Performed most of the RNA-Seq analysis and follow up bioinformatics studies, contributed to manuscript writing and figure preparation.

GG - Performed part of the RNA-Seq data analysis and in silico studies to identify miRNA clusters.

SO - Performed part of the in silico analysis to identify miRNA clusters.

EK - Contributed to experimental design.

AP - Contributed to the analysis of IncRNAs

PAFG - Contributed to data analysis, manuscript writing and figure preparation.

LOFP - Led the experimental design and data interpretation and contributed to manuscript writing and figure preparation.

\section{References}

1. Gebert LFR, MacRae IJ: Regulation of microRNA function in animals. Nat Rev Mol Cell Biol 2019, 20(1):21-37.

2. Park CY, Choi YS, McManus MT: Analysis of microRNA knockouts in mice. Hum Mol Genet 2010, 19(R2):R169-175.

3. Jansson MD, Lund AH: MicroRNA and cancer. Mol Oncol 2012, 6(6):590-610.

4. Piwecka M, Rolle K, Belter A, Barciszewska AM, Zywicki M, Michalak M, Nowak S, NaskretBarciszewska MZ, Barciszewski J: Comprehensive analysis of microRNA expression profile in malignant glioma tissues. Mol Oncol 2015, 9(7):1324-1340.

5. Chen Y, Stallings RL: Differential patterns of microRNA expression in neuroblastoma are correlated with prognosis, differentiation, and apoptosis. Cancer Res 2007, 67(3):976-983.

6. Alcantara Llaguno S, Sun D, Pedraza AM, Vera E, Wang Z, Burns DK, Parada LF: Cell-of-origin susceptibility to glioblastoma formation declines with neural lineage restriction. Nat Neurosci 2019, 22(4):545-555.

7. Johnsen JI, Dyberg C, Wickstrom M: Neuroblastoma-A Neural Crest Derived Embryonal Malignancy. Front Mol Neurosci 2019, 12:9.

8. Ahir BK, Ozer H, Engelhard HH, Lakka SS: MicroRNAs in glioblastoma pathogenesis and therapy: A comprehensive review. Crit Rev Oncol Hematol 2017, 120:22-33.

9. Prodromidou K, Matsas R: Species-Specific miRNAs in Human Brain Development and Disease. Front Cell Neurosci 2019, 13:559.

10. Bian S, Sun T: Functions of noncoding RNAs in neural development and neurological diseases. Mol Neurobiol 2011, 44(3):359-373. 
11. Silber J, Lim DA, Petritsch C, Persson Al, Maunakea AK, Yu M, Vandenberg SR, Ginzinger DG, James $\mathrm{CD}$, Costello JF et al: miR-124 and miR-137 inhibit proliferation of glioblastoma multiforme cells and induce differentiation of brain tumor stem cells. BMC Med 2008, 6:14.

12. Godlewski J, Nowicki MO, Bronisz A, Williams S, Otsuki A, Nuovo G, Raychaudhury A, Newton HB, Chiocca EA, Lawler S: Targeting of the Bmi-1 oncogene/stem cell renewal factor by microRNA-128 inhibits glioma proliferation and self-renewal. Cancer Res 2008, 68(22):9125-9130.

13. Sun Y, Luo ZM, Guo XM, Su DF, Liu X: An updated role of microRNA-124 in central nervous system disorders: a review. Front Cell Neurosci 2015, 9:193.

14. Lee ST, Chu K, Im WS, Yoon HJ, Im JY, Park JE, Park KH, Jung KH, Lee SK, Kim M et al: Altered microRNA regulation in Huntington's disease models. Exp Neurol 2011, 227(1):172-179.

15. Muinos-Gimeno M, Guidi M, Kagerbauer B, Martin-Santos R, Navines R, Alonso P, Menchon JM, Gratacos M, Estivill X, Espinosa-Parrilla Y: Allele variants in functional MicroRNA target sites of the neurotrophin-3 receptor gene (NTRK3) as susceptibility factors for anxiety disorders. Hum Mutat 2009, 30(7):1062-1071.

16. Wright C, Turner JA, Calhoun VD, Perrone-Bizzozero N: Potential Impact of miR-137 and Its Targets in Schizophrenia. Front Genet 2013, 4:58.

17. Smalheiser NR, Lugli G, Zhang H, Rizavi H, Cook EH, Dwivedi Y: Expression of microRNAs and other small RNAs in prefrontal cortex in schizophrenia, bipolar disorder and depressed subjects. PLoS One 2014, 9(1):e86469.

18. Santos MC, Tegge AN, Correa BR, Mahesula S, Kohnke LQ, Qiao M, Ferreira MA, Kokovay E, Penalva LO: miR-124, -128, and -137 Orchestrate Neural Differentiation by Acting on Overlapping Gene Sets Containing a Highly Connected Transcription Factor Network. Stem Cells 2016, 34(1):220-232.

19. Skalsky RL, Cullen BR: Reduced expression of brain-enriched microRNAs in glioblastomas permits targeted regulation of a cell death gene. PLoS One 2011, 6(9):e24248.

20. Tamim S, Vo DT, Uren PJ, Qiao M, Bindewald E, Kasprzak WK, Shapiro BA, Nakaya HI, Burns SC, Araujo PR et al: Genomic analyses reveal broad impact of miR-137 on genes associated with malignant transformation and neuronal differentiation in glioblastoma cells. PLoS One 2014, 9(1):e85591.

21. Hanna J, Hossain GS, Kocerha J: The Potential for microRNA Therapeutics and Clinical Research. Front Genet 2019, 10:478.

22. Nowakowski TJ, Rani N, Golkaram M, Zhou HR, Alvarado B, Huch K, West JA, Leyrat A, Pollen AA, Kriegstein AR et al: Regulation of cell-type-specific transcriptomes by microRNA networks during human brain development. Nat Neurosci 2018, 21(12):1784-1792.

23. Lai X, Eberhardt M, Schmitz U, Vera J: Systems biology-based investigation of cooperating microRNAs as monotherapy or adjuvant therapy in cancer. Nucleic Acids Res 2019, 47(15):77537766.

24. Hubert CG, Rivera M, Spangler LC, Wu Q, Mack SC, Prager BC, Couce M, McLendon RE, Sloan AE, Rich JN: A Three-Dimensional Organoid Culture System Derived from Human Glioblastomas 
Recapitulates the Hypoxic Gradients and Cancer Stem Cell Heterogeneity of Tumors Found In Vivo. Cancer Res 2016, 76(8):2465-2477.

25. Mao P, Joshi K, Li J, Kim SH, Li P, Santana-Santos L, Luthra S, Chandran UR, Benos PV, Smith L et al: Mesenchymal glioma stem cells are maintained by activated glycolytic metabolism involving aldehyde dehydrogenase 1A3. Proc Natl Acad Sci U S A 2013, 110(21):8644-8649.

26. Kutner RH, Zhang XY, Reiser J: Production, concentration and titration of pseudotyped HIV-1-based lentiviral vectors. Nat Protoc 2009, 4(4):495-505.

27. Certo MT, Ryu BY, Annis JE, Garibov M, Jarjour J, Rawlings DJ, Scharenberg AM: Tracking genome engineering outcome at individual DNA breakpoints. Nat Methods 2011, 8(8):671-676.

28. Goldman MJ, Craft B, Hastie M, Repecka K, McDade F, Kamath A, Banerjee A, Luo Y, Rogers D, Brooks AN et al: Visualizing and interpreting cancer genomics data via the Xena platform. Nat Biotechnol 2020, 38(6):675-678.

29. Brennan CW, Verhaak RG, McKenna A, Campos B, Noushmehr H, Salama SR, Zheng S, Chakravarty D, Sanborn JZ, Berman SH et al: The somatic genomic landscape of glioblastoma. Cel/ 2013, 155(2):462-477.

30. Schulte JH, Schowe B, Mestdagh P, Kaderali L, Kalaghatgi P, Schlierf S, Vermeulen J, Brockmeyer B, Pajtler K, Thor T et al: Accurate prediction of neuroblastoma outcome based on miRNA expression profiles. Int J Cancer 2010, 127(10):2374-2385.

31. D'Urso PI, D'Urso OF, Storelli C, Mallardo M, Gianfreda CD, Montinaro A, Cimmino A, Pietro C, Marsigliante S: miR-155 is up-regulated in primary and secondary glioblastoma and promotes tumour growth by inhibiting GABA receptors. Int J Oncol 2012, 41(1):228-234.

32. Huang HY, Lin YC, Li J, Huang KY, Shrestha S, Hong HC, Tang Y, Chen YG, Jin CN, Yu Y et al: miRTarBase 2020: updates to the experimentally validated microRNA-target interaction database. Nucleic Acids Res 2020, 48(D1):D148-D154.

33. Bray NL, Pimentel H, Melsted P, Pachter L: Near-optimal probabilistic RNA-seq quantification. Nat Biotechnol 2016, 34(5):525-527.

34. Soneson C, Love MI, Robinson MD: Differential analyses for RNA-seq: transcript-level estimates improve gene-level inferences. F1000Res 2015, 4:1521.

35. Love MI, Huber W, Anders S: Moderated estimation of fold change and dispersion for RNA-seq data with DESeq2. Genome Bio/ 2014, 15(12):550.

36. Agarwal V, Bell GW, Nam JW, Bartel DP: Predicting effective microRNA target sites in mammalian mRNAs. Elife 2015, 4.

37. Volders PJ, Anckaert J, Verheggen K, Nuytens J, Martens L, Mestdagh P, Vandesompele J: LNCipedia 5: towards a reference set of human long non-coding RNAs. Nucleic Acids Res 2019, 47(D1):D135D139.

38. Du L, Schageman JJ, Subauste MC, Saber B, Hammond SM, Prudkin L, Wistuba, II, Ji L, Roth JA, Minna JD et al: miR-93, miR-98, and miR-197 regulate expression of tumor suppressor gene FUS1. Mol Cancer Res 2009, 7(8):1234-1243. 
39. Mi H, Muruganujan A, Ebert D, Huang X, Thomas PD: PANTHER version 14: more genomes, a new PANTHER GO-slim and improvements in enrichment analysis tools. Nucleic Acids Res 2019, 47(D1):D419-D426.

40. Supek F, Bosnjak M, Skunca N, Smuc T: REVIGO summarizes and visualizes long lists of gene ontology terms. PLoS One 2011, 6(7):e21800.

41. Ge SX, Jung D, Yao R: ShinyGO: a graphical gene-set enrichment tool for animals and plants. Bioinformatics 2020, 36(8):2628-2629.

42. Lambert SA, Jolma A, Campitelli LF, Das PK, Yin Y, Albu M, Chen X, Taipale J, Hughes TR, Weirauch MT: The Human Transcription Factors. Cell 2018, 172(4):650-665.

43. Shannon P, Markiel A, Ozier O, Baliga NS, Wang JT, Ramage D, Amin N, Schwikowski B, Ideker T: Cytoscape: a software environment for integrated models of biomolecular interaction networks. Genome Res 2003, 13(11):2498-2504.

44. Szklarczyk D, Gable AL, Lyon D, Junge A, Wyder S, Huerta-Cepas J, Simonovic M, Doncheva NT, Morris JH, Bork P et al: STRING v11: protein-protein association networks with increased coverage, supporting functional discovery in genome-wide experimental datasets. Nucleic Acids Res 2019, 47(D1):D607-D613.

45. Kocak H, Ackermann S, Hero B, Kahlert Y, Oberthuer A, Juraeva D, Roels F, Theissen J, Westermann F, Deubzer $\mathrm{H}$ et al: Hox-C9 activates the intrinsic pathway of apoptosis and is associated with spontaneous regression in neuroblastoma. Cell Death Dis 2013, 4:e586.

46. Garcia DM, Baek D, Shin C, Bell GW, Grimson A, Bartel DP: Weak seed-pairing stability and high target-site abundance decrease the proficiency of Isy- 6 and other microRNAs. Nat Struct Mol Biol 2011, 18(10):1139-1146.

47. Suzuki R, Shimodaira H: Pvclust: an R package for assessing the uncertainty in hierarchical clustering. Bioinformatics 2006, 22(12):1540-1542.

48. Foucquier J, Guedj M: Analysis of drug combinations: current methodological landscape. Pharmacol Res Perspect 2015, 3(3):e00149.

49. Stupp R, Hegi ME, Mason WP, van den Bent MJ, Taphoorn MJ, Janzer RC, Ludwin SK, Allgeier A, Fisher $\mathrm{B}$, Belanger $\mathrm{K}$ et al: Effects of radiotherapy with concomitant and adjuvant temozolomide versus radiotherapy alone on survival in glioblastoma in a randomised phase III study: 5-year analysis of the EORTC-NCIC trial. Lancet Oncol2009, 10(5):459-466.

50. Johnson BE, Mazor T, Hong C, Barnes M, Aihara K, McLean CY, Fouse SD, Yamamoto S, Ueda H, Tatsuno $\mathrm{K}$ et al: Mutational analysis reveals the origin and therapy-driven evolution of recurrent glioma. Science 2014, 343(6167):189-193.

51. Pahlman S, Ruusala Al, Abrahamsson L, Mattsson ME, Esscher T: Retinoic acid-induced differentiation of cultured human neuroblastoma cells: a comparison with phorbolester-induced differentiation. Cell Differ 1984, 14(2):135-144.

52. Matthay KK, Villablanca JG, Seeger RC, Stram DO, Harris RE, Ramsay NK, Swift P, Shimada H, Black CT, Brodeur GM et al: Treatment of high-risk neuroblastoma with intensive chemotherapy, 
radiotherapy, autologous bone marrow transplantation, and 13-cis-retinoic acid. Children's Cancer Group. N Engl J Med 1999, 341(16):1165-1173.

53. Zhao Z, Ma X, Hsiao TH, Lin G, Kosti A, Yu X, Suresh U, Chen Y, Tomlinson GE, Pertsemlidis A et al: A high-content morphological screen identifies novel microRNAs that regulate neuroblastoma cell differentiation. Oncotarget 2014, 5(9):2499-2512.

54. Greene CS, Krishnan A, Wong AK, Ricciotti E, Zelaya RA, Himmelstein DS, Zhang R, Hartmann BM, Zaslavsky E, Sealfon SC et al: Understanding multicellular function and disease with human tissuespecific networks. Nat Genet 2015, 47(6):569-576.

55. Lim YC, Roberts TL, Day BW, Harding A, Kozlov S, Kijas AW, Ensbey KS, Walker DG, Lavin MF: A role for homologous recombination and abnormal cell-cycle progression in radioresistance of gliomainitiating cells. Mol Cancer Ther 2012, 11(9):1863-1872.

56. Lim YC, Roberts TL, Day BW, Stringer BW, Kozlov S, Fazry S, Bruce ZC, Ensbey KS, Walker DG, Boyd AW et al: Increased sensitivity to ionizing radiation by targeting the homologous recombination pathway in glioma initiating cells. Mol Onco/ 2014, 8(8):1603-1615.

57. Arun G, Aggarwal D, Spector DL: MALAT1 Long Non-Coding RNA: Functional Implications. Noncoding RNA 2020, 6(2).

58. Klec C, Prinz F, Pichler M: Involvement of the long noncoding RNA NEAT1 in carcinogenesis. Mol Oncol 2019, 13(1):46-60.

59. Chen W, Xu XK, Li JL, Kong KK, Li H, Chen C, He J, Wang F, Li P, Ge XS et al: MALAT1 is a prognostic factor in glioblastoma multiforme and induces chemoresistance to temozolomide through suppressing miR-203 and promoting thymidylate synthase expression. Oncotarget 2017, 8(14):22783-22799.

60. Zhen Y, Nan Y, Guo S, Zhang L, Li G, Yue S, Liu X: Knockdown of NEAT1 repressed the malignant progression of glioma through sponging miR-107 and inhibiting CDK14. J Cell Physiol 2019, 234(7):10671-10679.

61. Yang X, Xiao Z, Du X, Huang L, Du G: Silencing of the long non-coding RNA NEAT1 suppresses glioma stem-like properties through modulation of the miR-107/CDK6 pathway. Oncol Rep 2017, 37(1):555-562.

62. Chen Q, Cai J, Wang Q, Wang Y, Liu M, Yang J, Zhou J, Kang C, Li M, Jiang C: Long Noncoding RNA NEAT1, Regulated by the EGFR Pathway, Contributes to Glioblastoma Progression Through the WNT/beta-Catenin Pathway by Scaffolding EZH2. Clin Cancer Res 2018, 24(3):684-695.

63. He C, Jiang B, Ma J, Li Q: Aberrant NEAT1 expression is associated with clinical outcome in high grade glioma patients. APMIS 2016, 124(3):169-174.

64. Choudhary S, Burns SC, Mirsafian H, Li W, Vo DT, Qiao M, Lei X, Smith AD, Penalva LO: Genomic analyses of early responses to radiation inglioblastoma reveal new alterations at transcription,splicing, and translation levels. Sci Rep 2020, 10(1):8979.

65. Li N, Cui M, Yu P, Li Q: Correlations of IncRNAs with cervical lymph node metastasis and prognosis of papillary thyroid carcinoma. Onco Targets Ther 2019, 12:1269-1278. 
66. Bowman RL, Wang Q, Carro A, Verhaak RG, Squatrito M: GlioVis data portal for visualization and analysis of brain tumor expression datasets. Neuro Oncol 2017, 19(1):139-141.

67. Shao T, Wang G, Chen H, Xie Y, Jin X, Bai J, Xu J, Li X, Huang J, Jin Y et al: Survey of miRNA-miRNA cooperative regulation principles across cancer types. Brief Bioinform 2019, 20(5):1621-1638.

68. Selbach M, Schwanhausser B, Thierfelder N, Fang Z, Khanin R, Rajewsky N: Widespread changes in protein synthesis induced by microRNAs. Nature 2008, 455(7209):58-63.

69. Jackson AL, Linsley PS: Recognizing and avoiding siRNA off-target effects for target identification and therapeutic application. Nat Rev Drug Discov 2010, 9(1):57-67.

70. Arvey A, Larsson E, Sander C, Leslie CS, Marks DS: Target mRNA abundance dilutes microRNA and siRNA activity. Mol Syst Biol 2010, 6:363.

71. Chen X, Zhao W, Yuan Y, Bai Y, Sun Y, Zhu W, Du Z: MicroRNAs tend to synergistically control expression of genes encoding extensively-expressed proteins in humans. PeerJ 2017, 5:e3682.

72. Bandi $N$, Vassella $E$ : miR-34a and miR-15a/16 are co-regulated in non-small cell lung cancer and control cell cycle progression in a synergistic and Rb-dependent manner. Mol Cancer 2011, 10:55.

73. Akbari Moqadam F, Lange-Turenhout EA, Aries IM, Pieters R, den Boer ML: MiR-125b, miR-100 and miR-99a co-regulate vincristine resistance in childhood acute lymphoblastic leukemia. Leuk Res 2013, 37(10):1315-1321.

74. Lai X, Gupta SK, Schmitz U, Marquardt S, Knoll S, Spitschak A, Wolkenhauer O, Putzer BM, Vera J: MiR-205-5p and miR-342-3p cooperate in the repression of the E2F1 transcription factor in the context of anticancer chemotherapy resistance. Theranostics 2018, 8(4):1106-1120.

75. Frampton AE, Castellano L, Colombo T, Giovannetti E, Krell J, Jacob J, Pellegrino L, Roca-Alonso L, Funel N, Gall TM et al: MicroRNAs cooperatively inhibit a network of tumor suppressor genes to promote pancreatic tumor growth and progression. Gastroenterology 2014, 146(1):268-277 e218.

76. Malhotra M, Sekar TV, Ananta JS, Devulapally R, Afjei R, Babikir HA, Paulmurugan R, Massoud TF: Targeted nanoparticle delivery of therapeutic antisense microRNAs presensitizes glioblastoma cells to lower effective doses of temozolomide in vitro and in a mouse model. Oncotarget 2018, 9(30):21478-21494.

77. Qadir MI, Parveen A, Ali M: Cdc42: Role in Cancer Management. Chem Biol Drug Des 2015, 86(4):432439.

78. Mao F, Zhang J, Cheng X, Xu Q: miR-149 inhibits cell proliferation and enhances chemosensitivity by targeting CDC42 and BCL2 in neuroblastoma. Cancer Cell Int 2019, 19:357.

79. Shi C, Ren L, Sun C, Yu L, Bian X, Zhou X, Wen Y, Hua D, Zhao S, Luo W et al: miR-29a/b/c function as invasion suppressors for gliomas by targeting $\mathrm{CDC42}$ and predict the prognosis of patients. $\mathrm{Br} \mathrm{J}$ Cancer 2017, 117(7):1036-1047.

80. Jacobi N, Seeboeck R, Hofmann E, Eger A: ErbB Family Signalling: A Paradigm for Oncogene Addiction and Personalized Oncology. Cancers (Basel) 2017, 9(4).

81. Wang Z: ErbB Receptors and Cancer. Methods Mol Biol 2017, 1652:3-35. 
82. Roskoski R, Jr.: Small molecule inhibitors targeting the EGFR/ErbB family of protein-tyrosine kinases in human cancers. Pharmacol Res 2019, 139:395-411.

83. Juliandi B, Abematsu M, Nakashima K: Epigenetic regulation in neural stem cell differentiation. Dev Growth Differ 2010, 52(6):493-504.

84. Sun J, Gong X, Purow B, Zhao Z: Uncovering MicroRNA and Transcription Factor Mediated Regulatory Networks in Glioblastoma. PLoS Comput Biol 2012, 8(7):e1002488.

85. Beckers A, Van Peer G, Carter DR, Mets E, Althoff K, Cheung BB, Schulte JH, Mestdagh P, Vandesompele J, Marshall GM et al: MYCN-targeting miRNAs are predominantly downregulated during MYCNdriven neuroblastoma tumor formation. Oncotarget 2015, 6(7):5204-5216.

86. Martinez NJ, Ow MC, Barrasa MI, Hammell M, Sequerra R, Doucette-Stamm L, Roth FP, Ambros VR, Walhout AJ: A C. elegans genome-scale microRNA network contains composite feedback motifs with high flux capacity. Genes Dev 2008, 22(18):2535-2549.

87. Hobert 0 : Architecture of a microRNA-controlled gene regulatory network that diversifies neuronal cell fates. Cold Spring Harb Symp Quant Bio/ 2006, 71:181-188.

88. Xu T, Le TD, Liu L, Wang R, Sun B, Li J: Identifying Cancer Subtypes from miRNA-TF-mRNA Regulatory Networks and Expression Data. PLoS One 2016, 11(4):e0152792.

89. Yang WB, Hsu CC, Hsu TI, Liou JP, Chang KY, Chen PY, Liu JJ, Yang ST, Wang JY, Yeh SH et al: Increased activation of HDAC1/2/6 and Sp1 underlies therapeutic resistance and tumor growth in glioblastoma. Neuro Oncol 2020.

90. Tuthill MC, Wada RK, Arimoto JM, Sugino CN, Kanemaru KK, Takeuchi KK, Sidell N: N-myc oncogene expression in neuroblastoma is driven by Sp1 and Sp3. Mol Genet Metab 2003, 80(1-2):272-280.

91. Aygun N, Altungoz O: MYCN is amplified during $S$ phase, and cmyb is involved in controlling MYCN expression and amplification in MYCNamplified neuroblastoma cell lines. Mol Med Rep 2019, 19(1):345-361.

92. Siebzehnrubl FA, Silver DJ, Tugertimur B, Deleyrolle LP, Siebzehnrubl D, Sarkisian MR, Devers KG, Yachnis AT, Kupper MD, Neal D et al: The ZEB1 pathway links glioblastoma initiation, invasion and chemoresistance. EMBO Mol Med 2013, 5(8):1196-1212.

93. Li R, Li Y, Hu X, Lian H, Wang L, Fu H: Transcription factor 3 controls cell proliferation and migration in glioblastoma multiforme cell lines. Biochem Cell Biol 2016, 94(3):247-255.

94. Nozato M, Kaneko S, Nakagawara A, Komuro H: Epithelial-mesenchymal transition-related gene expression as a new prognostic marker for neuroblastoma. Int J Oncol 2013, 42(1):134-140.

95. Wu K, Li S, Bodhinathan K, Meyers C, Chen W, Campbell-Thompson M, Mclntyre L, Foster TC, Muzyczka N, Kumar A: Enhanced expression of Pctk1, Tcf12 and Ccnd1 in hippocampus of rats: Impact on cognitive function, synaptic plasticity and pathology. Neurobiol Learn Mem 2012, 97(1):69-80.

96. Godoy PR, Montaldi AP, Sakamoto-Hojo ET: HEB silencing induces anti-proliferative effects on U87MG cells cultured as neurospheres and monolayers. Mol Med Rep 2016, 14(6):5253-5260. 
97. Zhang J, Pham VVH, Liu L, Xu T, Truong B, Li J, Rao N, Le TD: Identifying miRNA synergism using multiple-intervention causal inference. BMC Bioinformatics 2019, 20(Suppl 23):613.

98. Schmitz U, Lai X, Winter F, Wolkenhauer O, Vera J, Gupta SK: Cooperative gene regulation by microRNA pairs and their identification using a computational workflow. Nucleic Acids Res 2014, 42(12):7539-7552.

99. Velasco MX, Kosti A, Guardia GDA, Santos MC, Tegge A, Qiao M, Correa BRS, Hernandez G, Kokovay $\mathrm{E}$, Galante PAF et al: Antagonism between the RNA-binding protein Musashi1 and miR-137 and its potential impact on neurogenesis and glioblastoma development. $R N A$ 2019, 25(7):768-782.

\section{Tables}

Due to technical limitations, table 1 is only available as a download in the Supplemental Files section.

\section{Figures}




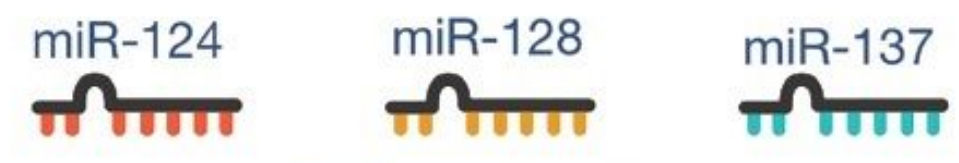

miRNA combination

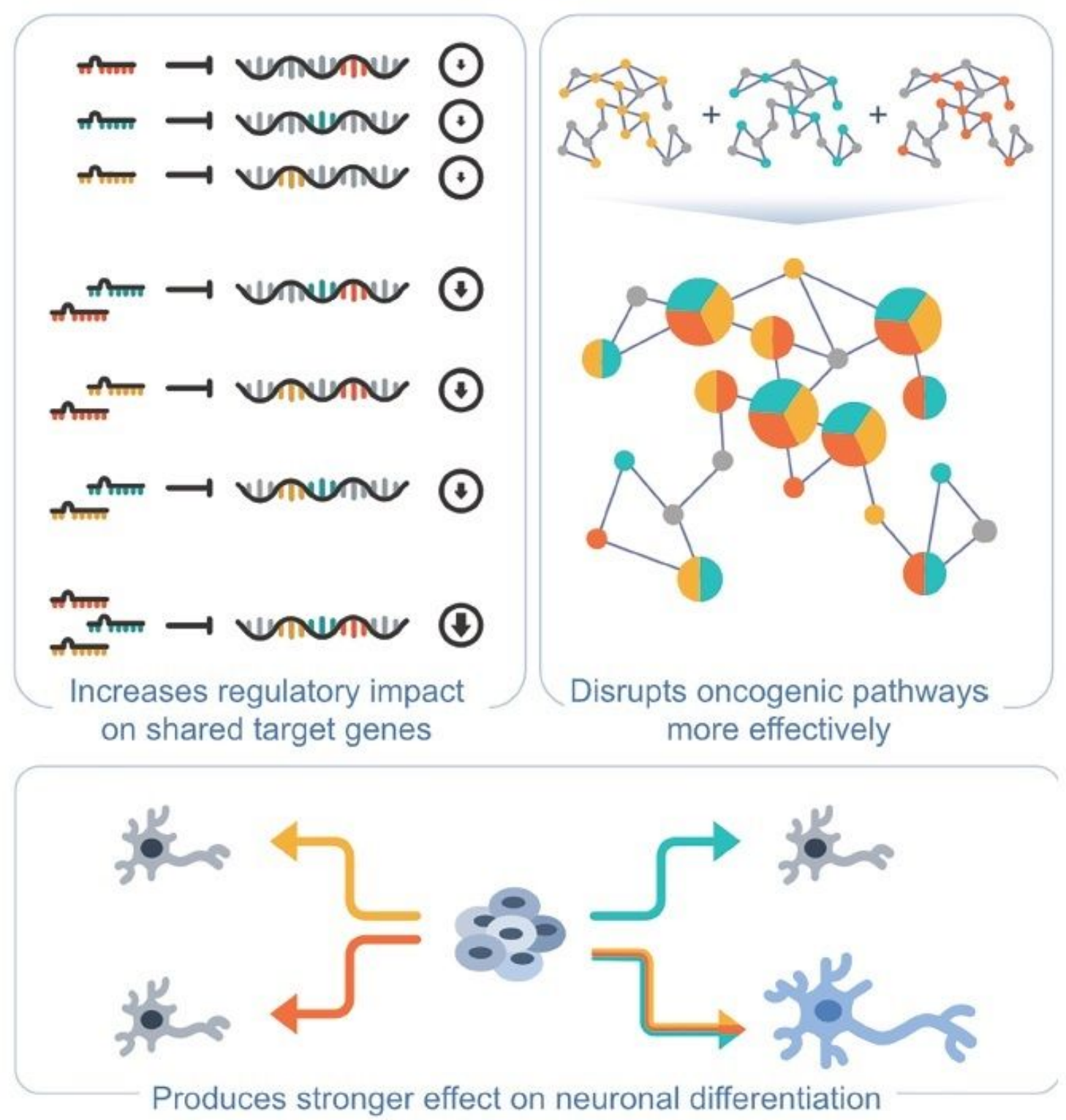

\section{Figure 1}

miR-124, miR-128, and miR-137 synergism. Model for synergistic interactions between miR-124, miR-128 and miR-137. Combined action of the three miRNAs on shared and associated targets produces a stronger regulatory effect. This includes a stronger repression of shared targets, increased effect on neuronal differentiation and broader and stronger impact on oncogenic pathways. 


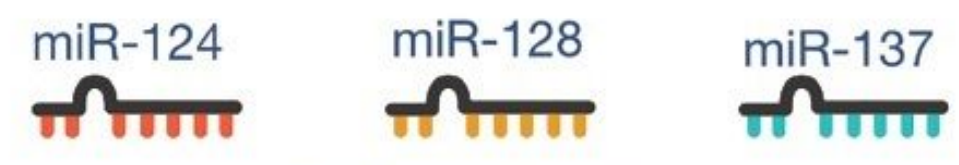

miRNA combination

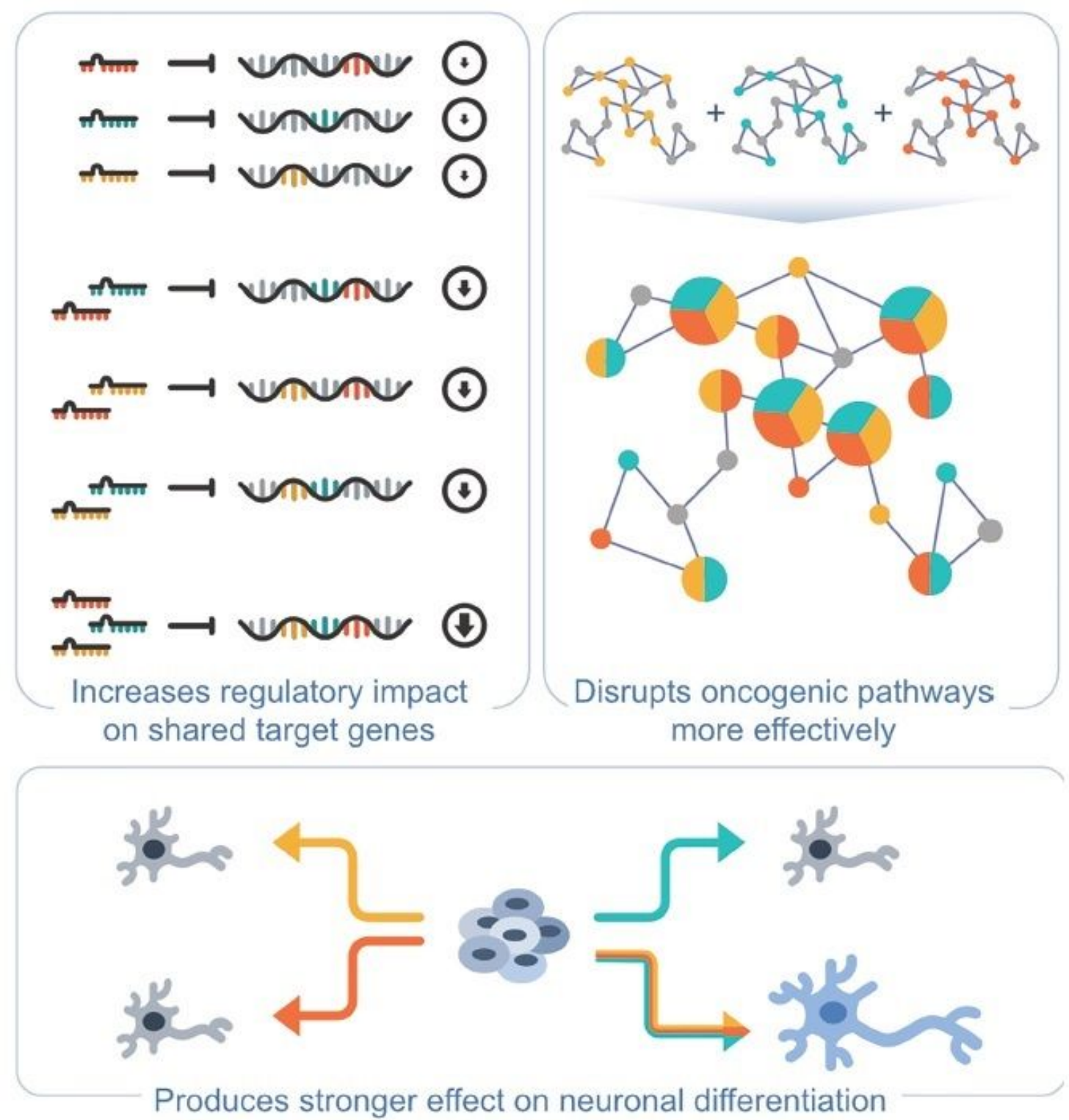

\section{Figure 1}

miR-124, miR-128, and miR-137 synergism. Model for synergistic interactions between miR-124, miR-128 and miR-137. Combined action of the three miRNAs on shared and associated targets produces a stronger regulatory effect. This includes a stronger repression of shared targets, increased effect on neuronal differentiation and broader and stronger impact on oncogenic pathways. 
A
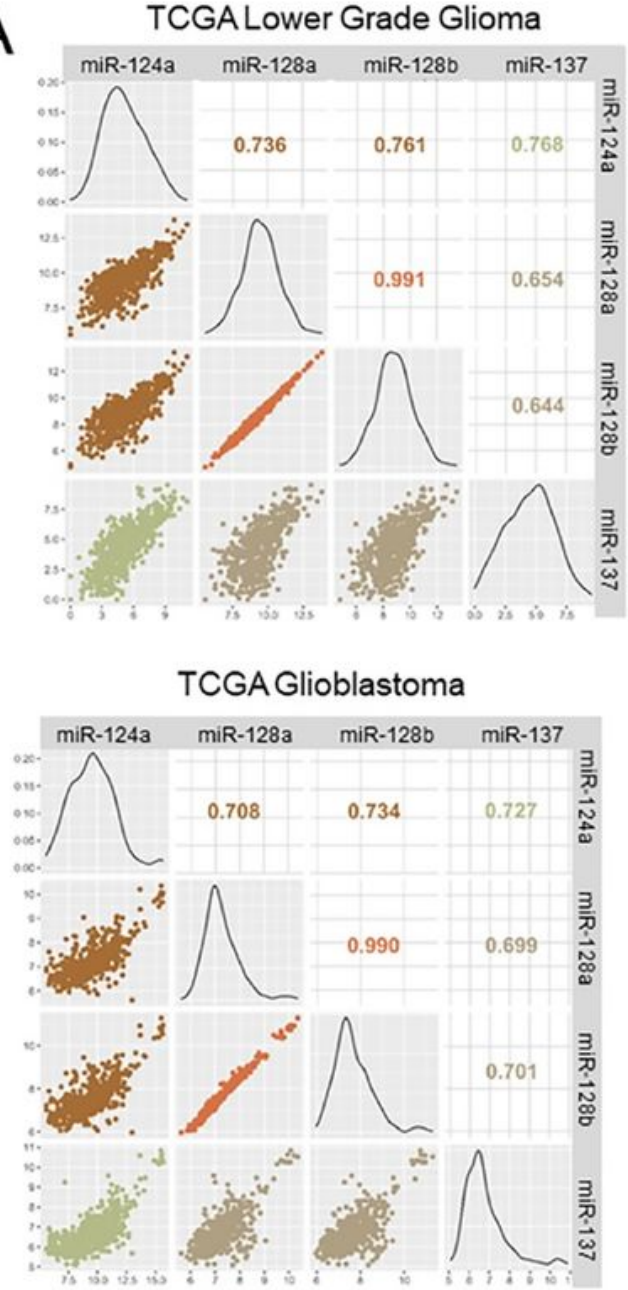

Neuroblastoma Schulte Study

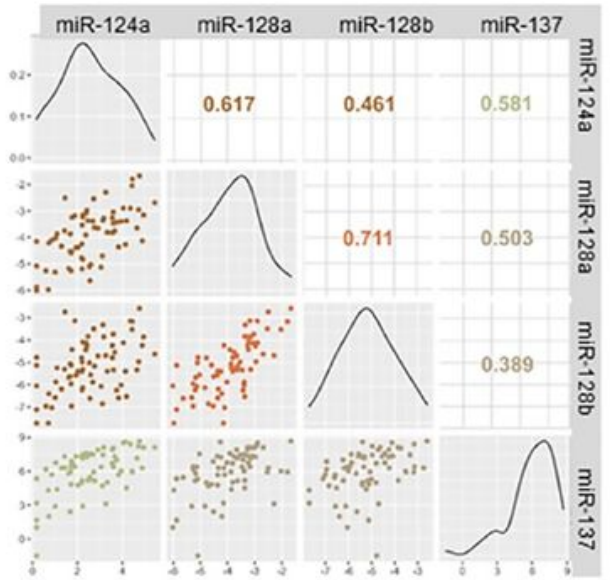

B TCGA Lower Grade Glioma

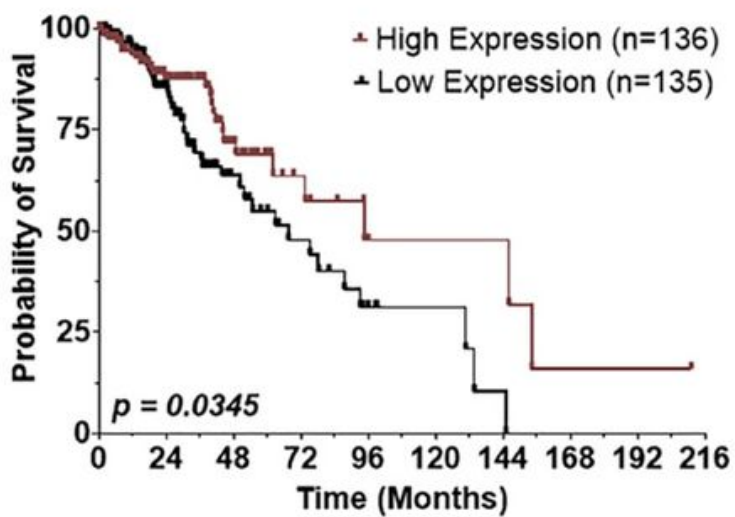

TCGA Lower Grade Glioma

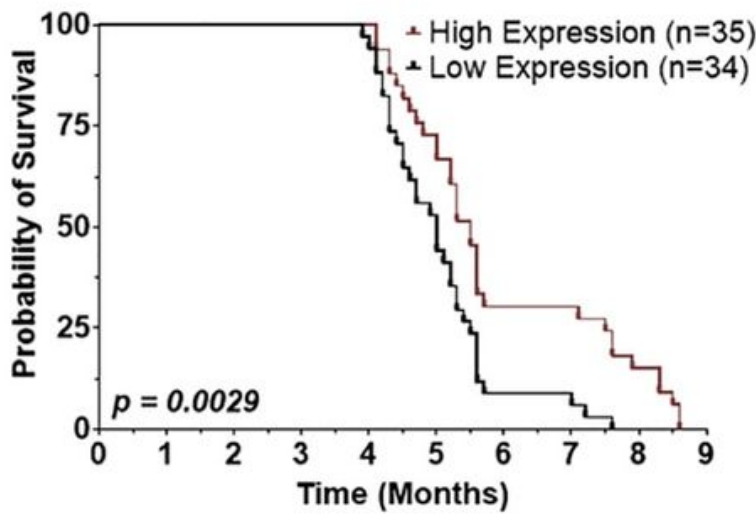

Neuroblastoma Schulte Study

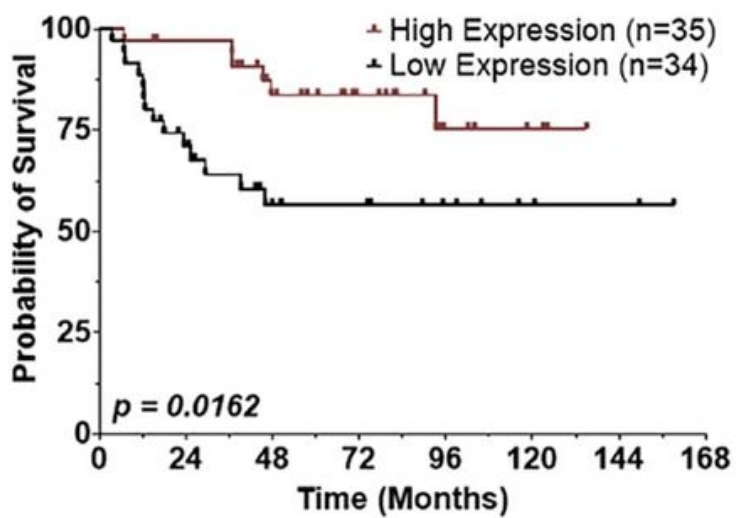

Figure 2

miR-124, miR-128, and miR-137 co-expression in glioma and neuroblastoma patients and impact on patient survival. A) miRNA expression correlation in patient samples from the TCGA LGG, TCGA GBM, and in neuroblastoma (Schulte study). B) Survival rates of patients expressing low vs. high miR-124, -128, and -137 in TCGA LGG, D'Urso GBM Study, and Schulte Neuroblastoma Study. 
A
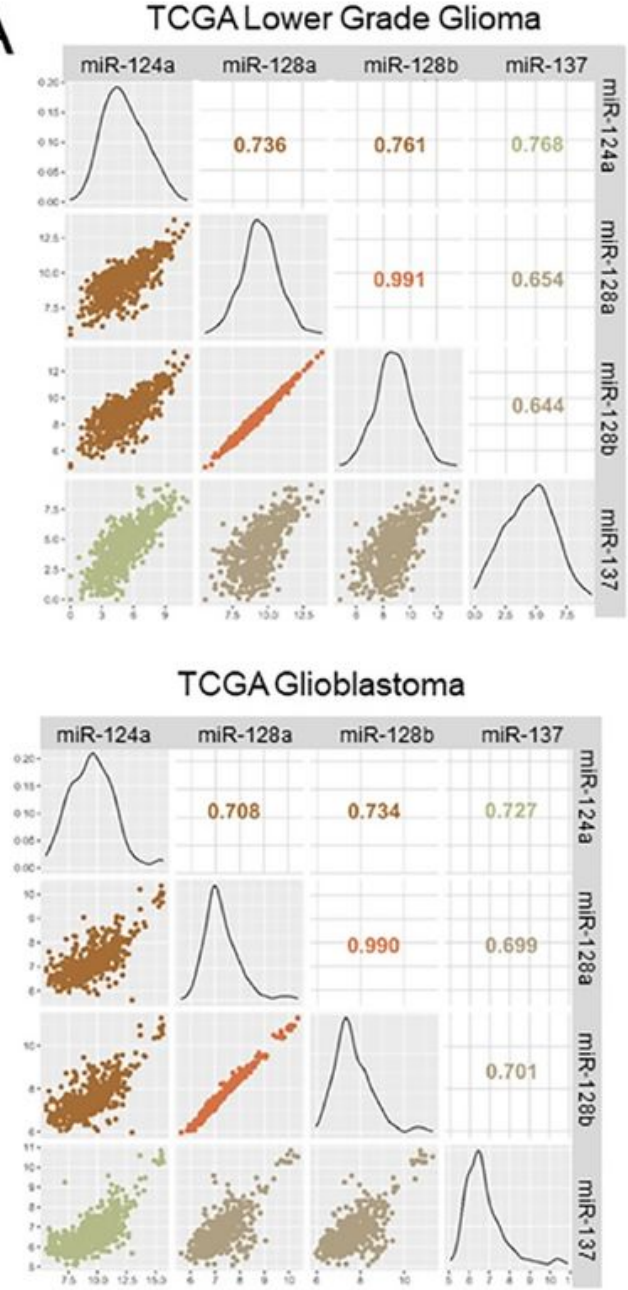

Neuroblastoma Schulte Study

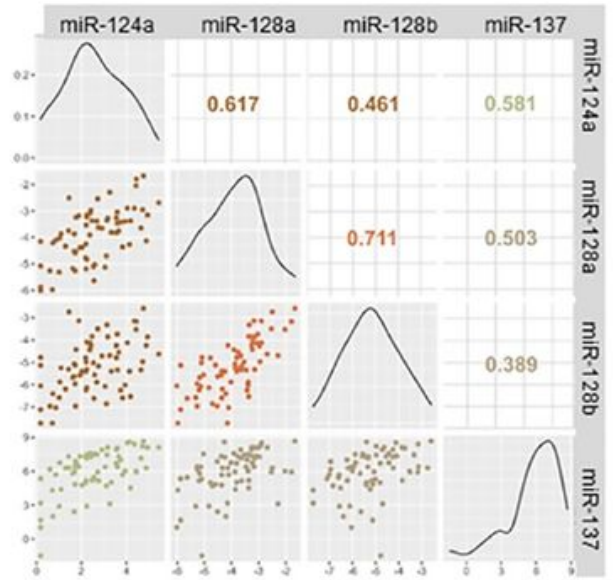

B TCGA Lower Grade Glioma

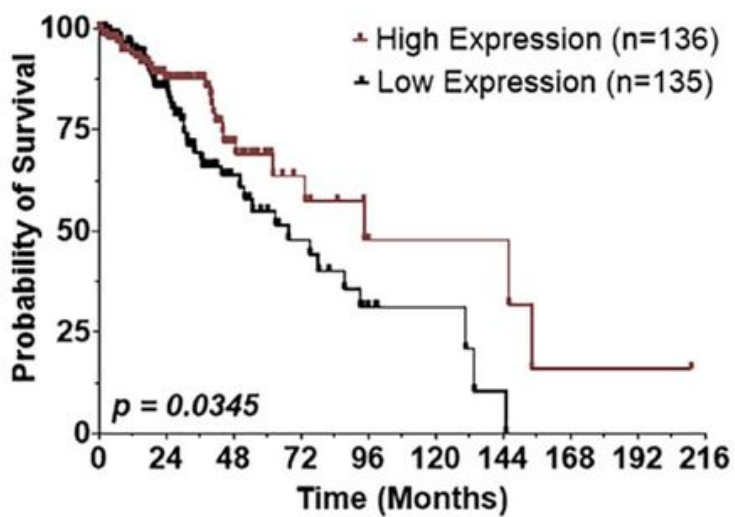

TCGA Lower Grade Glioma

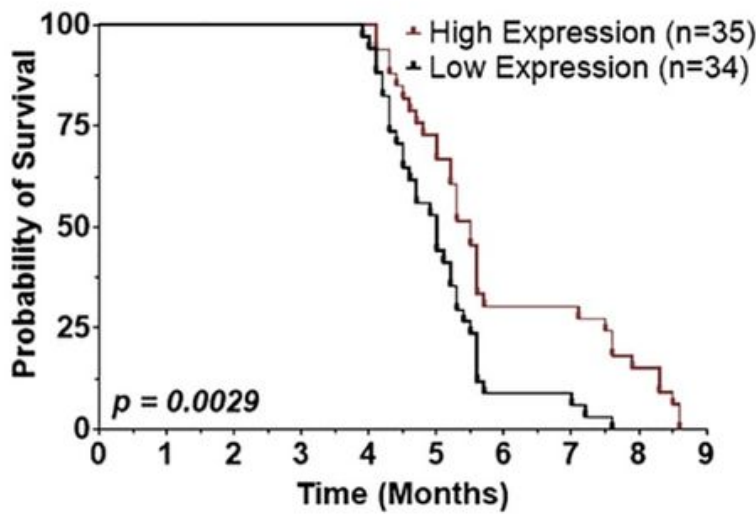

Neuroblastoma Schulte Study

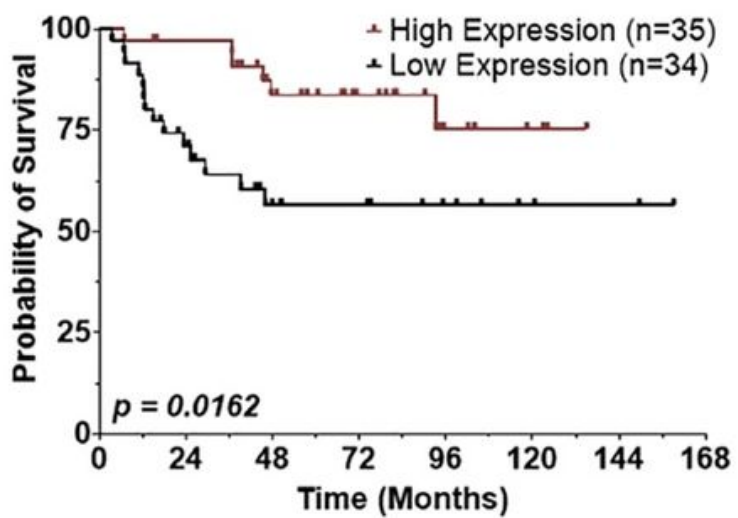

Figure 2

miR-124, miR-128, and miR-137 co-expression in glioma and neuroblastoma patients and impact on patient survival. A) miRNA expression correlation in patient samples from the TCGA LGG, TCGA GBM, and in neuroblastoma (Schulte study). B) Survival rates of patients expressing low vs. high miR-124, -128, and -137 in TCGA LGG, D'Urso GBM Study, and Schulte Neuroblastoma Study. 


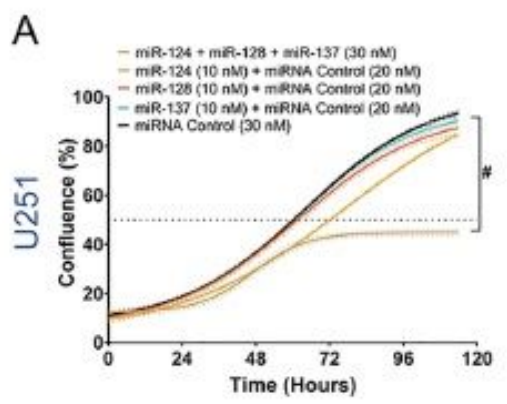

E
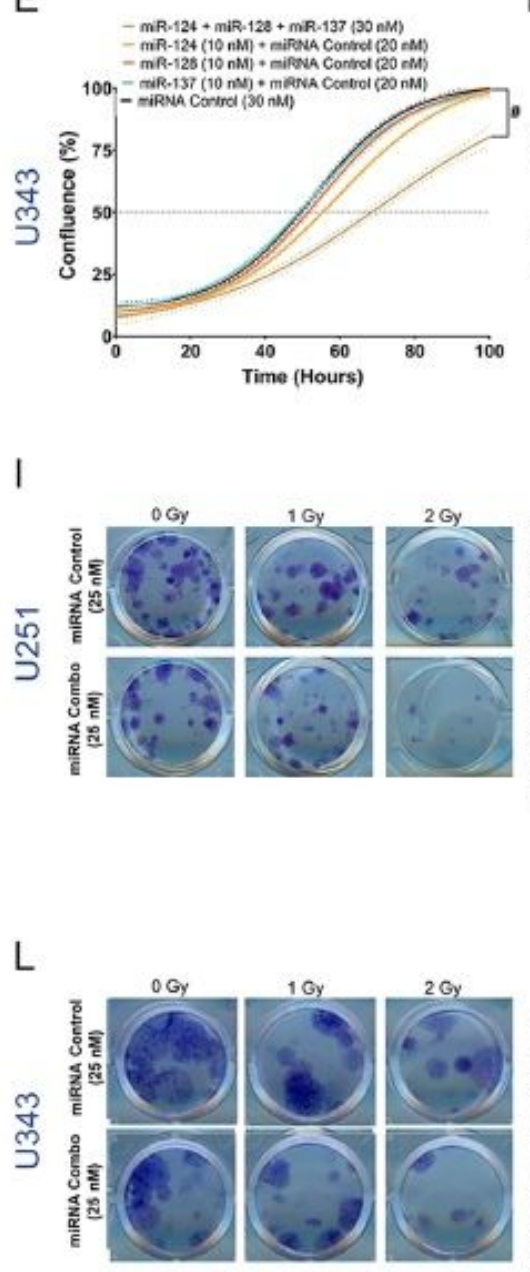

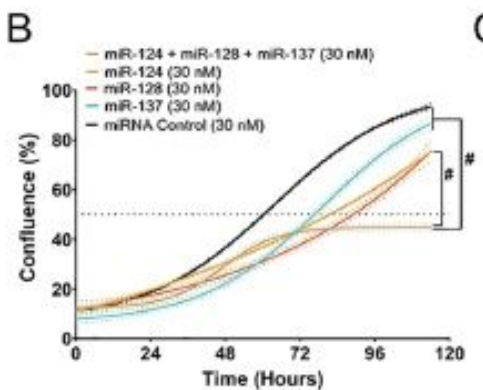

F
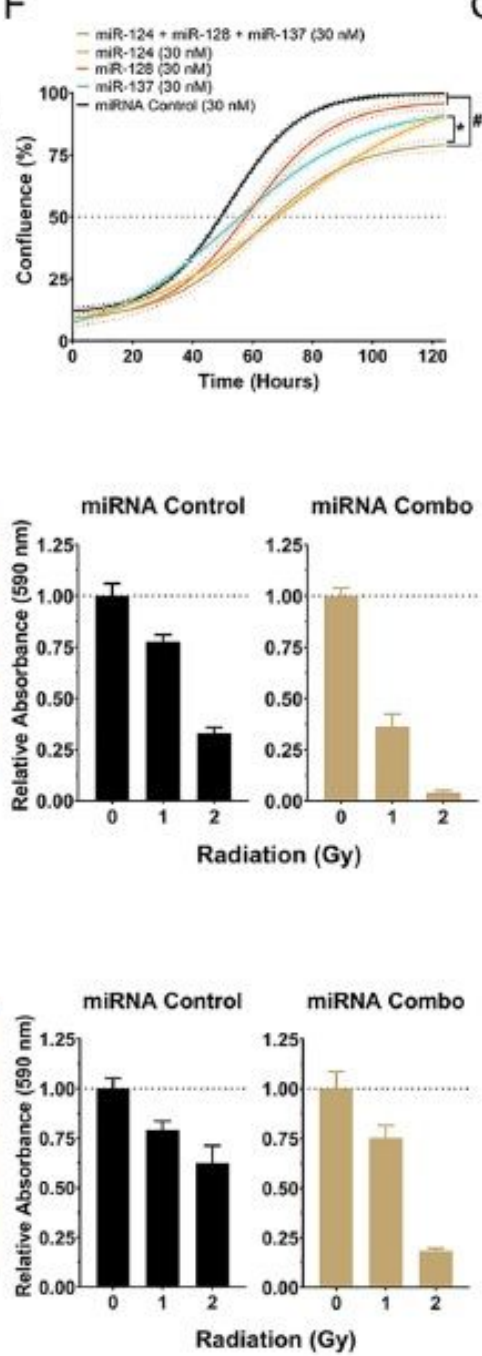

C

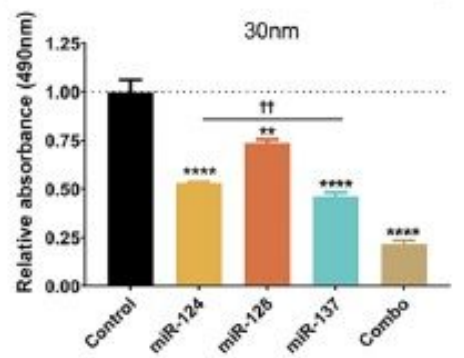

$\mathrm{H}$

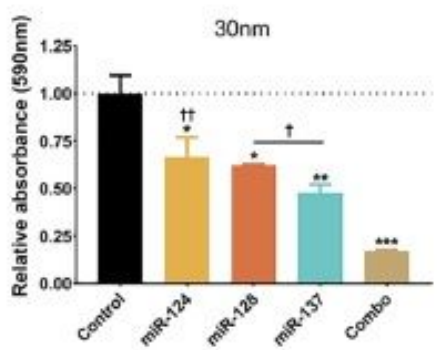

G
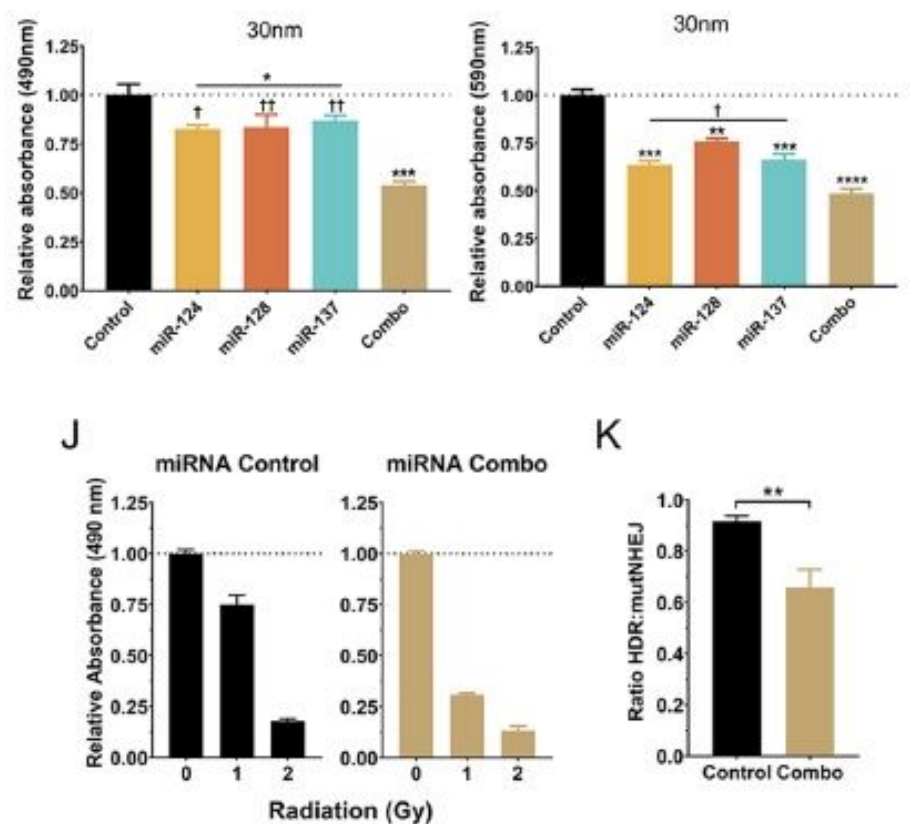

K

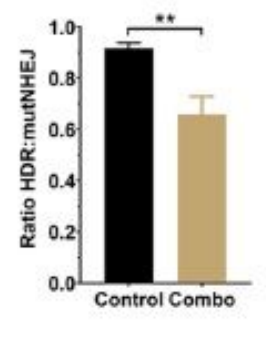

$\mathrm{N}$

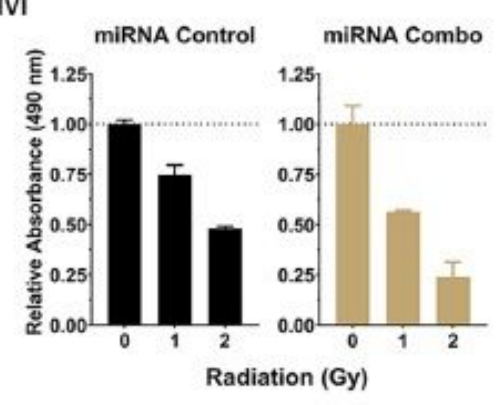

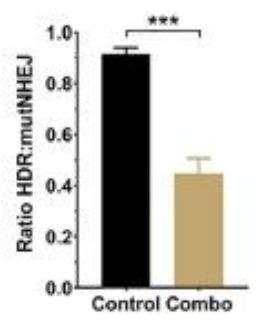

\section{Figure 3}

Synergistic effects of miR-124, miR-128, and miR-137 on glioblastoma cells. (A, E) Cell proliferation with live-cell imaging (Incucyte) of U251 and U343 cells following reverse transfection with low concentrations $(10 \mathrm{nM})$ of individual miRNAs and combination of the three miRNAs (total $30 \mathrm{nM})$. Effects of the combination were greater than expected additivity, indicating synergy based on linear and Bliss models (U251 Linear Cl: 0.339; Bliss Cl: 0.338; U343 Linear Cl: 0.152; Bliss Cl: 0.151). Tukey test for significance at 120 hours, $\#=p<0.0001$. $(B, F)$ Effects of miRNA combination on cell proliferation versus individual miRNAs at an equivalent concentration (30 nM). (C, G) Viability of GBM cells 48 hours after reverse transfection with individual miRNA mimics and the combination (30 nM). (D, H) Clonogenic ability of 
GBM cells after reverse transfection with individual miRNA mimics and the combination $(30 \mathrm{nM})$. $(\mathrm{l}, \mathrm{L})$ Left: representative aspects of U251 and U343 cells transfected with control or miRNA combination (miR$124,-128$ and -137) clonogenic ability following exposure to ionizing radiation; right, quantification of clonogenic assay results. Two-way ANOVA with Tukey test for multiple comparisons. p-adjusted values: ${ }^{*} \mathrm{p}<0.05 ; * \star * * \mathrm{p}<0.0001$. (J, M) Viability of U251 and U343 cells transfected with control or miRNA combination 48 hours after exposure to ionizing radiation. Two-way ANOVA with Tukey test for multiple comparisons. p-adjusted values: ${ }^{* \star} \mathrm{p}<0.001 ;{ }^{* \star \star *} \mathrm{p}<0.0001$. $(\mathrm{K}, \mathrm{N})$ Results of traffic light reporter assays displaying ratios of homologous recombination to mutant NHEJ of U251 and U343 cells transfected with control or miRNA combination 48 hours after transfection with the I-Scel plasmid. Student's t-test: ** $p$ $<0.01 ; * \star * p<0.001$.

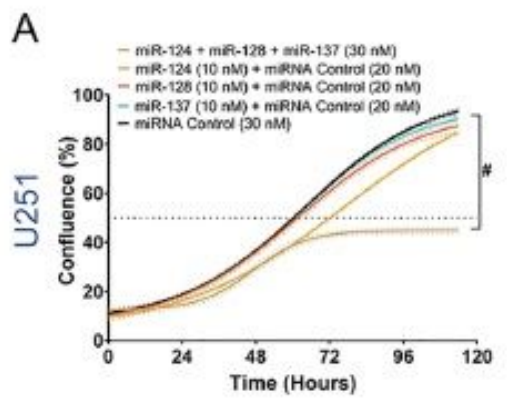

E
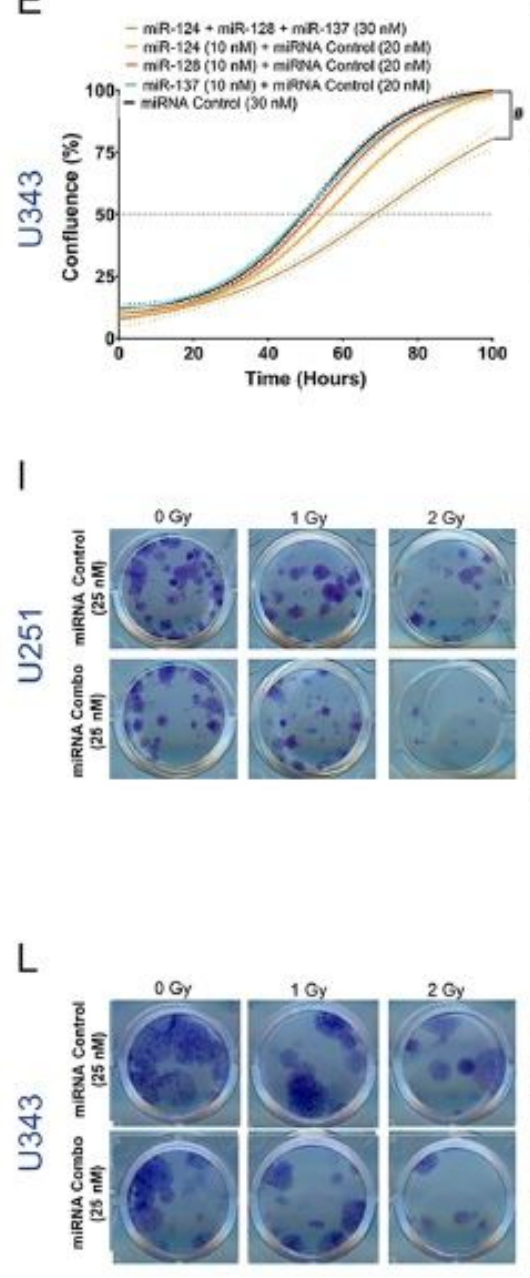

B

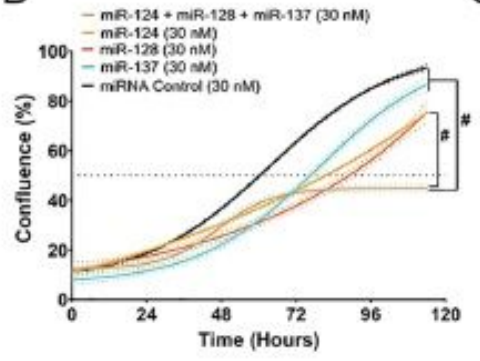

$\mathrm{F}$
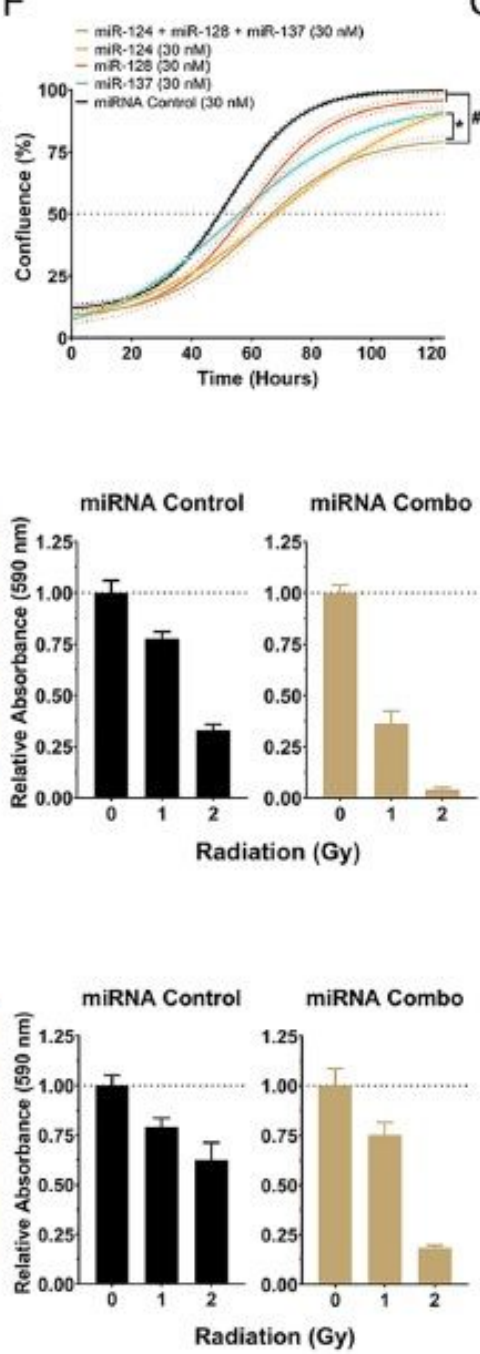

C

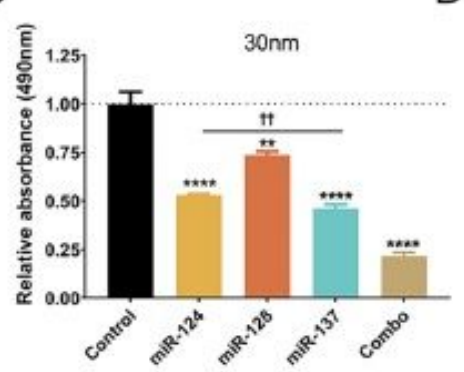

G
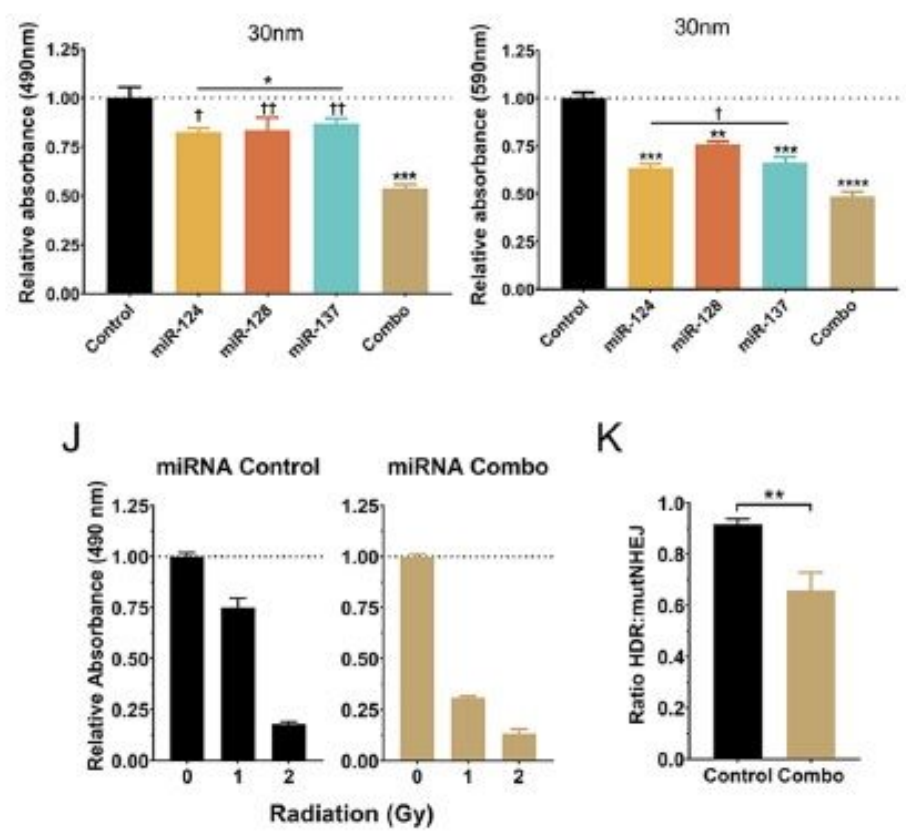

M

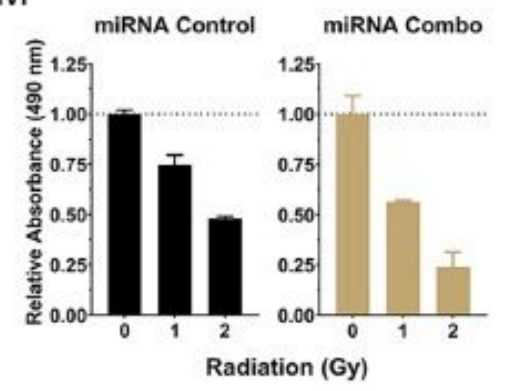

K

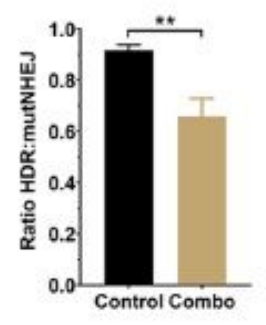

$\mathrm{N}$

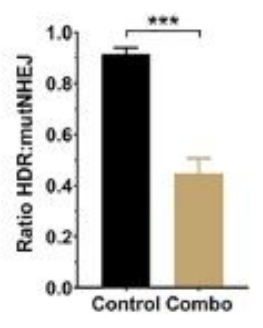




\section{Figure 3}

Synergistic effects of miR-124, miR-128, and miR-137 on glioblastoma cells. (A, E) Cell proliferation with live-cell imaging (Incucyte) of U251 and U343 cells following reverse transfection with low concentrations $(10 \mathrm{nM})$ of individual miRNAs and combination of the three miRNAs (total $30 \mathrm{nM}$ ). Effects of the combination were greater than expected additivity, indicating synergy based on linear and Bliss models (U251 Linear Cl: 0.339; Bliss Cl: 0.338; U343 Linear Cl: 0.152; Bliss Cl: 0.151). Tukey test for significance at 120 hours, $\#=p<0.0001$. (B, F) Effects of miRNA combination on cell proliferation versus individual miRNAs at an equivalent concentration (30 nM). $(C, G)$ Viability of GBM cells 48 hours after reverse transfection with individual miRNA mimics and the combination $(30 \mathrm{nM}) .(\mathrm{D}, \mathrm{H})$ Clonogenic ability of GBM cells after reverse transfection with individual miRNA mimics and the combination $(30 \mathrm{nM}) .(\mathrm{I}, \mathrm{L})$ Left: representative aspects of U251 and U343 cells transfected with control or miRNA combination (miR124, -128 and -137) clonogenic ability following exposure to ionizing radiation; right, quantification of clonogenic assay results. Two-way ANOVA with Tukey test for multiple comparisons. p-adjusted values: ${ }^{*} \mathrm{p}<0.05 ;{ }^{* \star \star \star} \mathrm{p}<0.0001$. (J, M) Viability of U251 and U343 cells transfected with control or miRNA combination 48 hours after exposure to ionizing radiation. Two-way ANOVA with Tukey test for multiple comparisons. p-adjusted values: ${ }^{* \star} \mathrm{p}<0.001 ;{ }^{* \star * *} \mathrm{p}<0.0001$. $(\mathrm{K}, \mathrm{N})$ Results of traffic light reporter assays displaying ratios of homologous recombination to mutant NHEJ of U251 and U343 cells transfected with control or miRNA combination 48 hours after transfection with the I-Scel plasmid. Student's t-test: ** $p$ $<0.01 ; * \star * p<0.001$. 
A

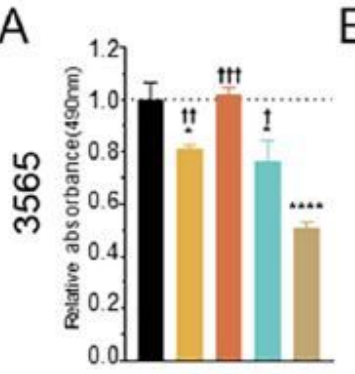

B
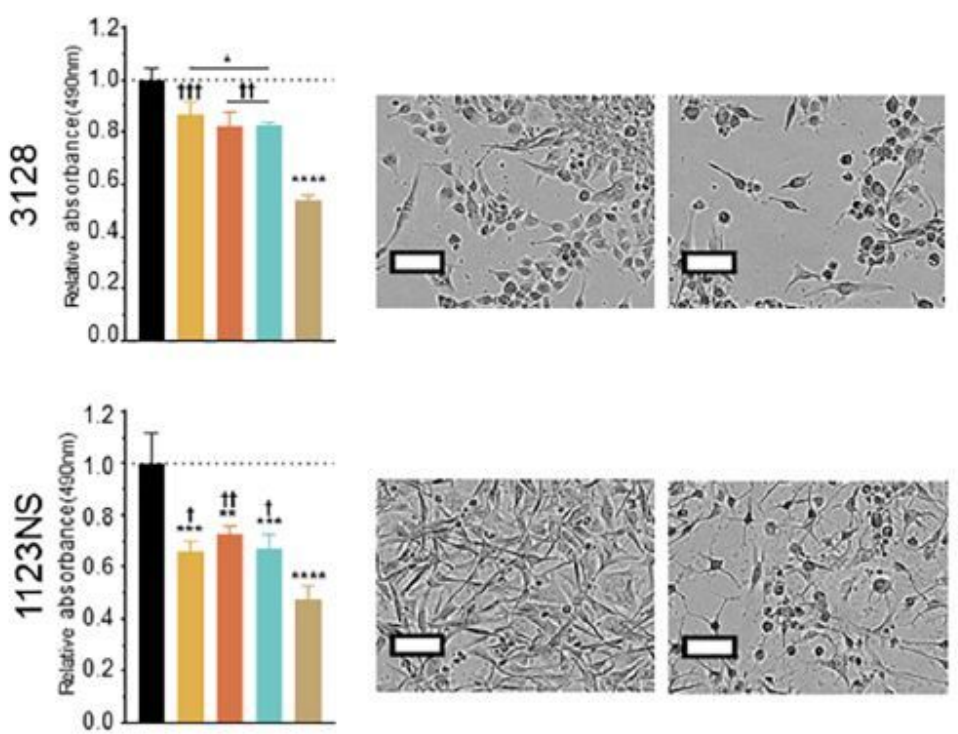

Mesenchymal
C
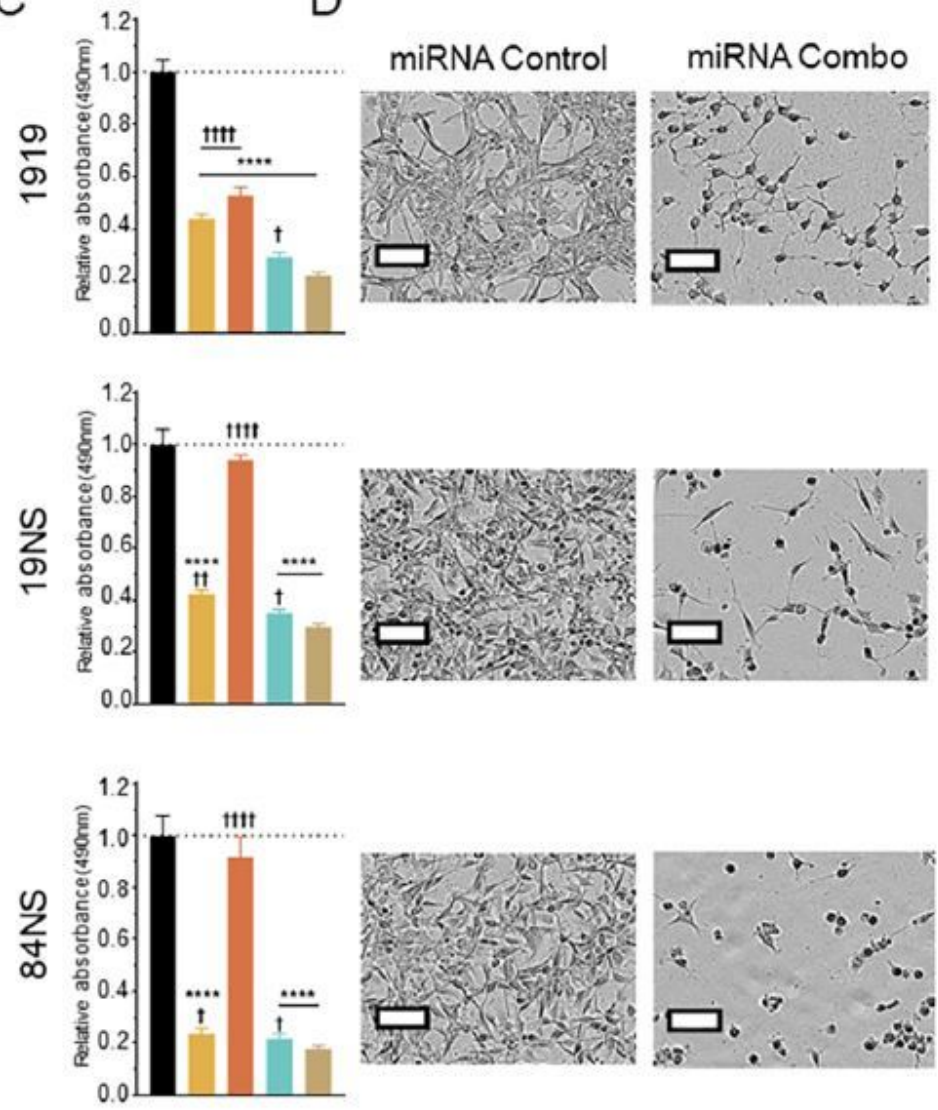

Proneural

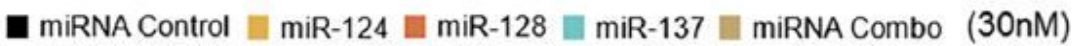

\section{Figure 4}

miRNA combination inhibits glioma stem cell phenotype. A) Mesenchymal glioma stem cell (GSC) viability 120 hours after reverse transfection with $30 \mathrm{nM}$ of single and combined miRNA mimics. B) Phenotypic changes of GSCs in (A). C) Proneural GSC viability 120 hours after reverse transfection with $30 \mathrm{nM}$ of single and combined miRNA mimics. D) Phenotypic changes of GSCs in (C). A one-way ANOVA with Tukey test for multiple comparisons was utilized for all experiments. $p$-values for comparisons against miRNA control: ${ }^{\star} p<0.05 ;{ }^{* \star} p<0.01 ; \star \star \star p<0.001 ; * \star \star \star p<<0.0001$. $p$-values for comparisons against miRNA Combo: $\uparrow p<0.05 ; \dagger+p<0.01 ; \dagger+t p<0.001 ; \dagger+\dagger+p<0.0001$. Scale bar represents 100 $\mu \mathrm{m}$. 
A

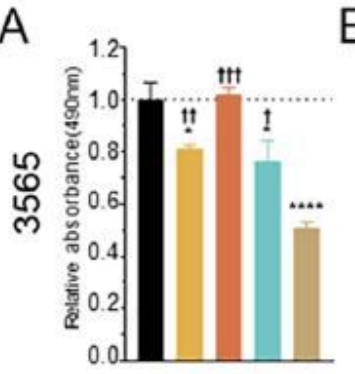

B
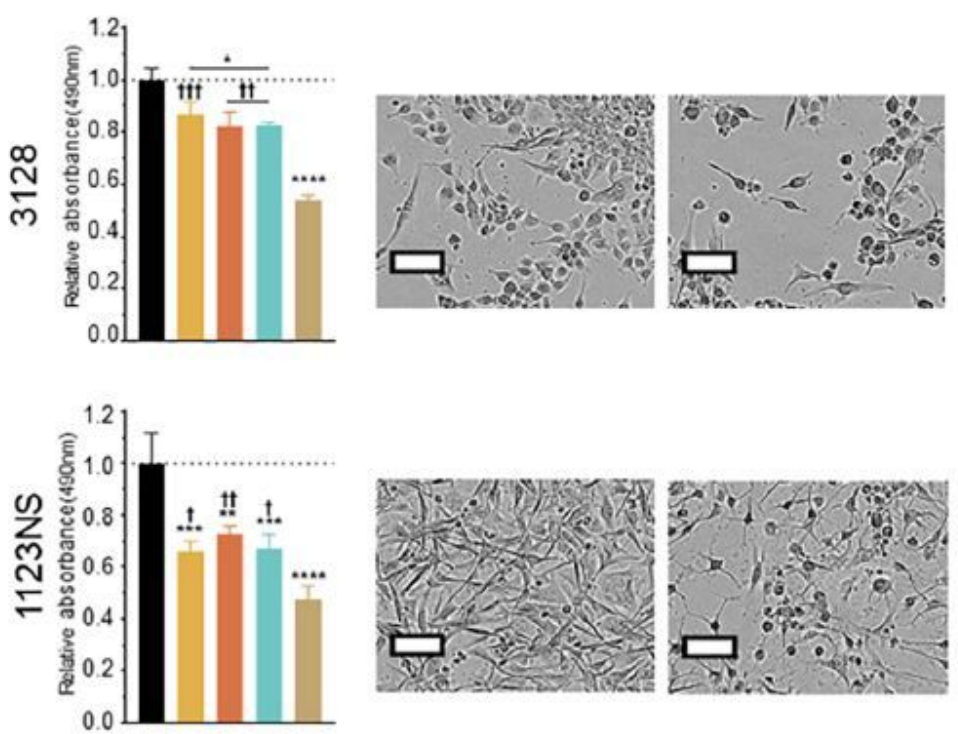

Mesenchymal
C
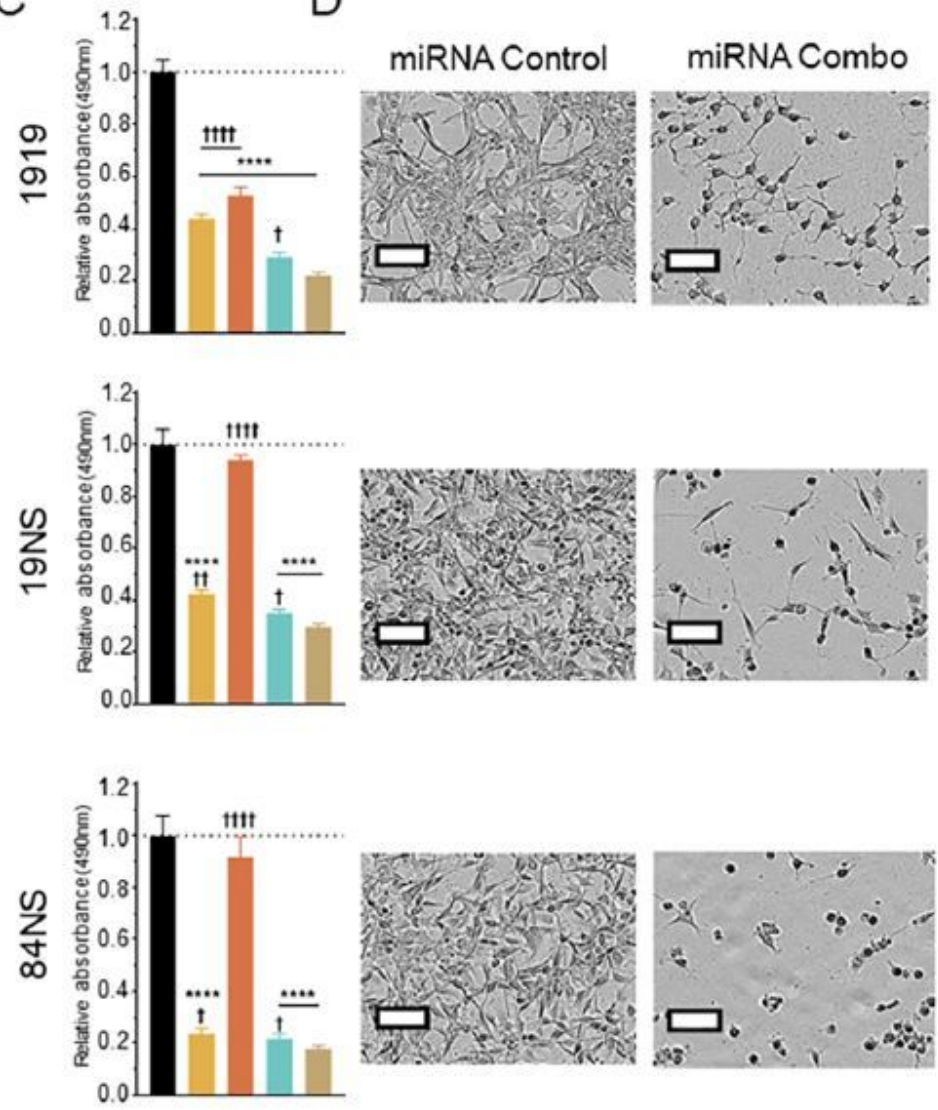

Proneural

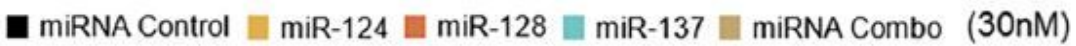

\section{Figure 4}

miRNA combination inhibits glioma stem cell phenotype. A) Mesenchymal glioma stem cell (GSC) viability 120 hours after reverse transfection with $30 \mathrm{nM}$ of single and combined miRNA mimics. B) Phenotypic changes of GSCs in (A). C) Proneural GSC viability 120 hours after reverse transfection with $30 \mathrm{nM}$ of single and combined miRNA mimics. D) Phenotypic changes of GSCs in (C). A one-way ANOVA with Tukey test for multiple comparisons was utilized for all experiments. $p$-values for comparisons against miRNA control: ${ }^{\star} p<0.05 ;{ }^{* \star} p<0.01 ; \star \star \star p<0.001 ; * \star \star \star p<<0.0001$. $p$-values for comparisons against miRNA Combo: $\uparrow p<0.05 ; \dagger+p<0.01 ; \dagger+t p<0.001 ; \dagger+\dagger+p<0.0001$. Scale bar represents 100 $\mu \mathrm{m}$. 

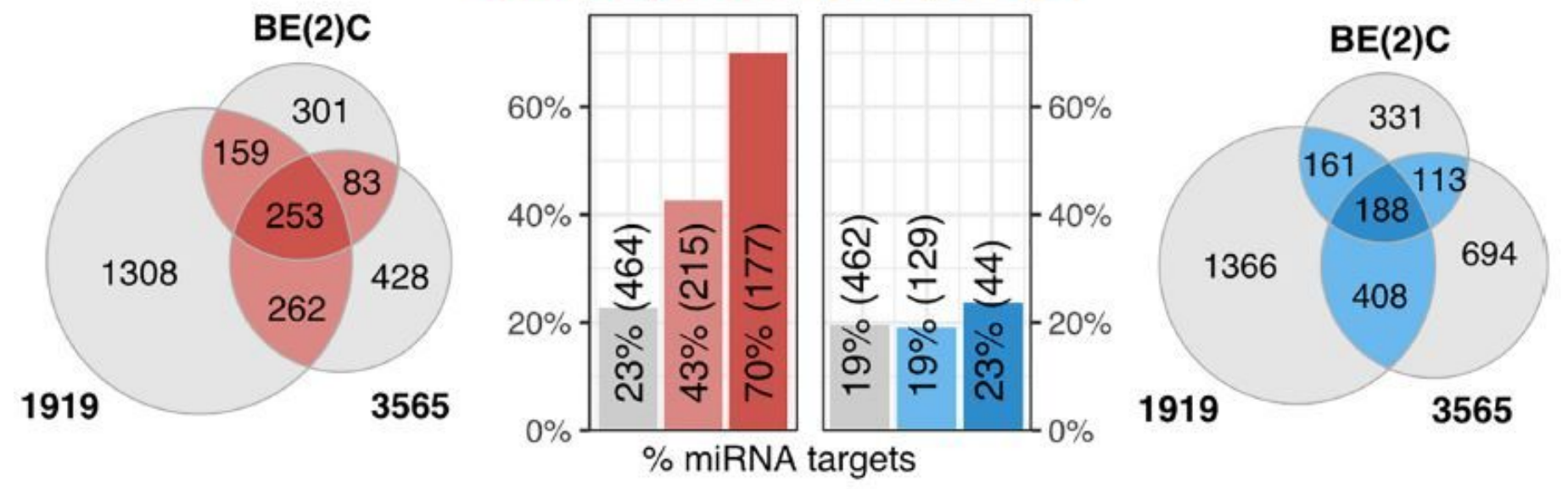

$\mathrm{B}$

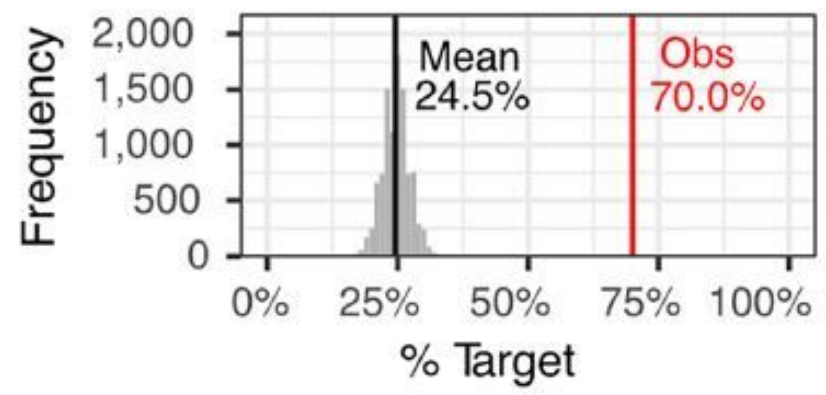

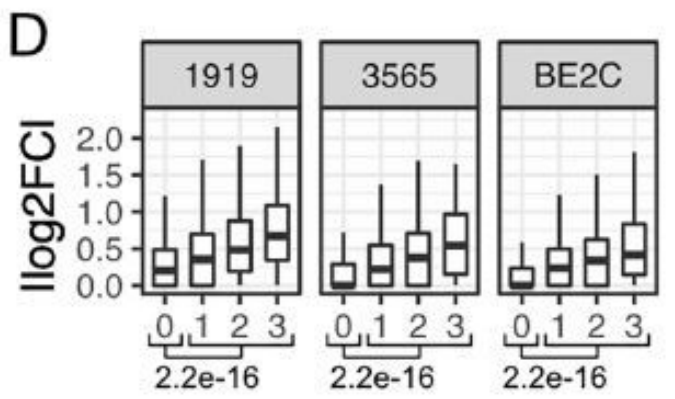

number of miRNAs targeting gene

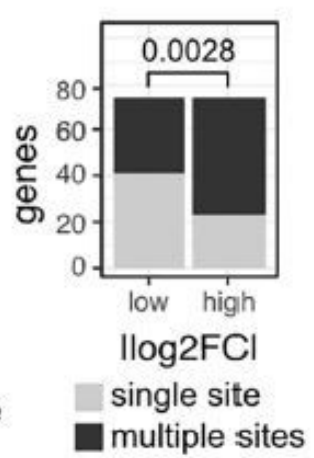

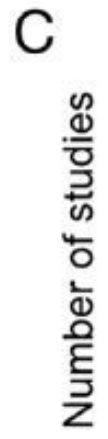

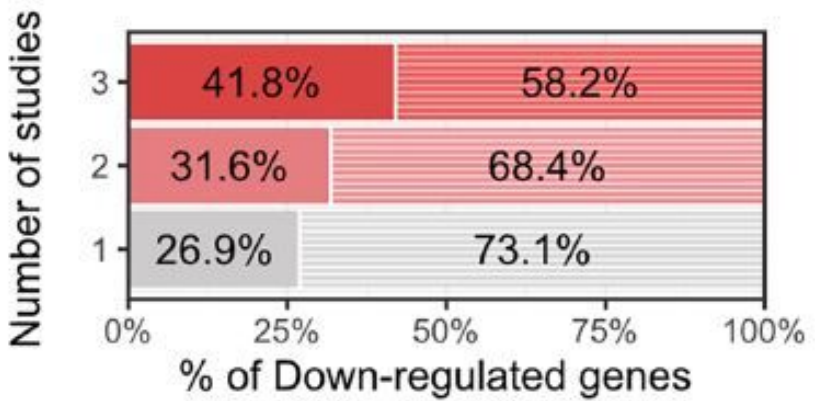

$\mathrm{E}$
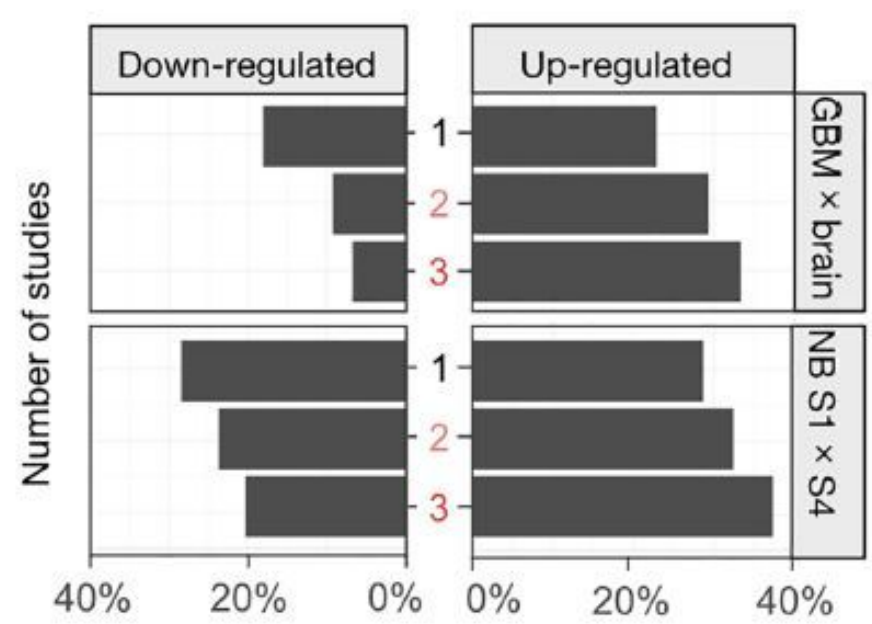

Figure 5

RNA-seq analysis of cells transfected with control and miRNA combo mimics. A) Overlap between results of RNA-seq studies done in BE(2)C, GSCs 1919, and 3565 transfected with control vs. miRNA combination (miR-124, -128, and -137) mimics. Bar graphs: percentage of genes targeted by at least one of the transfected miRNAs identified in one, two or all studies. B) Number of genes targeted by at least one of the three transfected miRNAs appearing in the overlap of the three studies is much higher than expected by chance ( $p$-value $=6.83 \mathrm{e}-66)$. C) Percentage of genes targeted by 2 or 3 of the transfected miRNAs appearing in the overlap of the three studies is much higher than the number observed in single 
studies. D) Left: Genes targeted by all three miRNAs show greater decrease in expression versus genes targeted by two or a single miRNA. Right: Genes with multiple miRNA binding sites displayed higher silencing level in comparison to genes with a single miRNA binding site. E) Percentage of miRNA target genes in all three, two, or single studies with increased expression in GBM in relation to normal brain (cortex) and stage 4 neuroblastoma compared to stage 1.

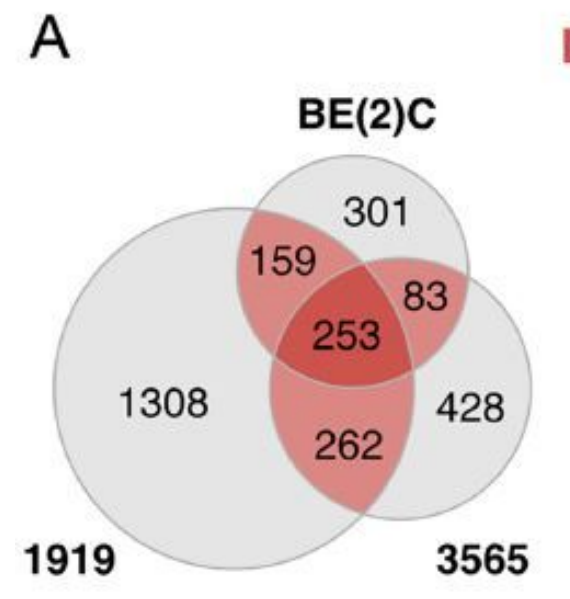

\section{Down-regulated Up-regulated}
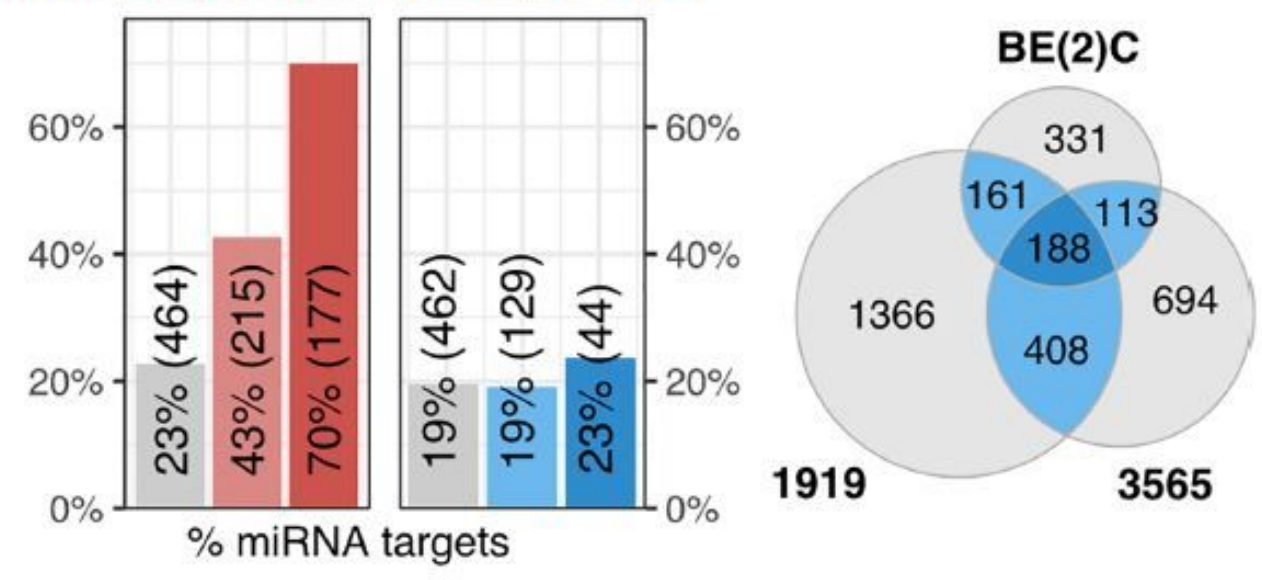

$\mathrm{B}$
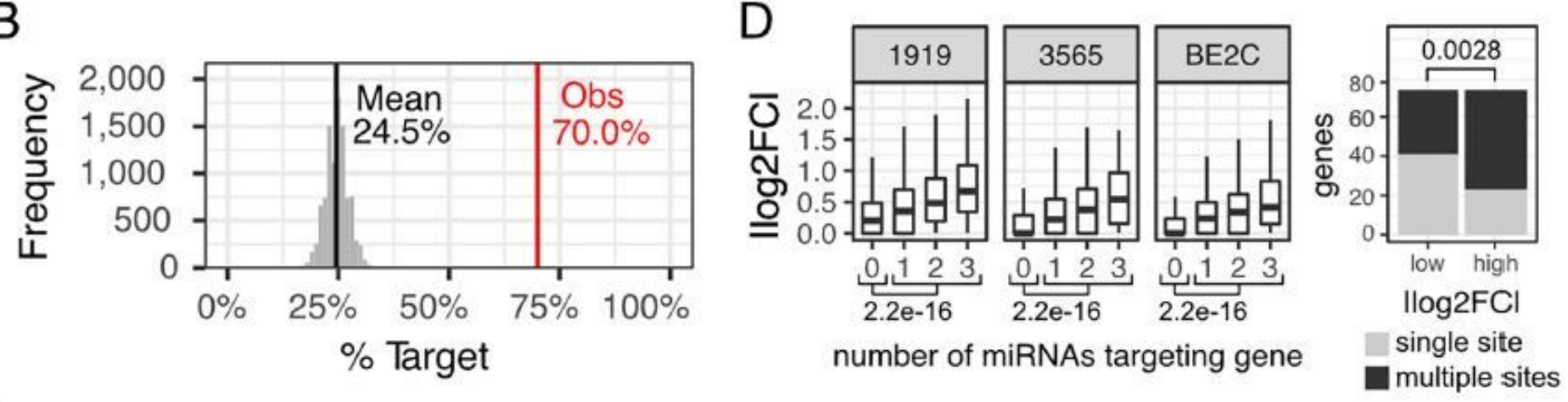

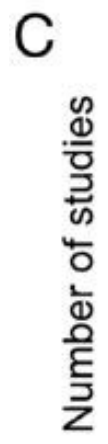

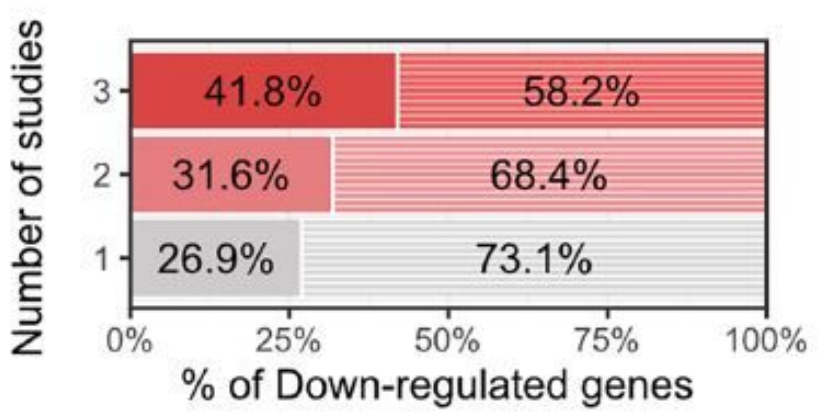

E

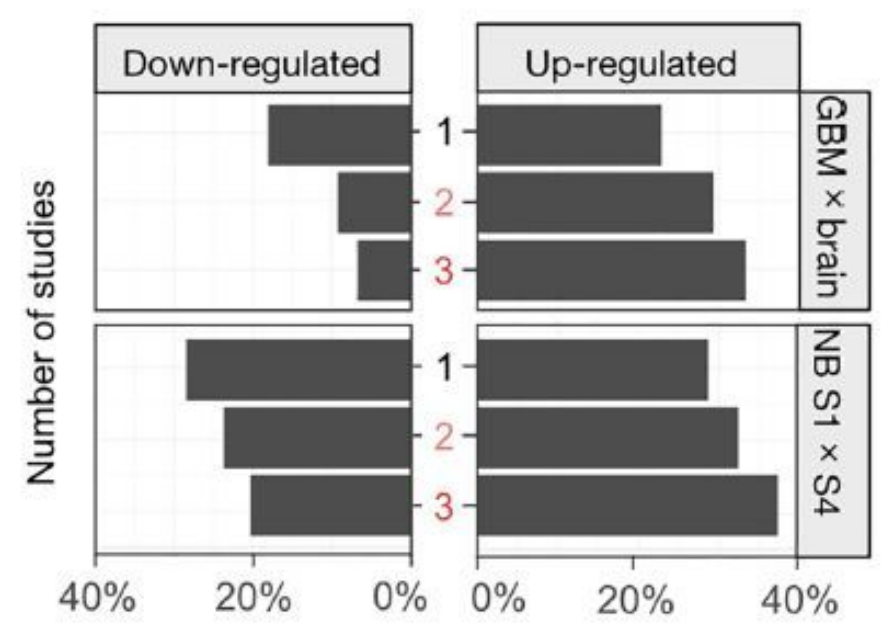

Figure 5

RNA-seq analysis of cells transfected with control and miRNA combo mimics. A) Overlap between results of RNA-seq studies done in BE(2)C, GSCs 1919, and 3565 transfected with control vs. miRNA 
combination (miR-124, -128, and -137) mimics. Bar graphs: percentage of genes targeted by at least one of the transfected miRNAs identified in one, two or all studies. B) Number of genes targeted by at least one of the three transfected miRNAs appearing in the overlap of the three studies is much higher than expected by chance ( $p$-value $=6.83 \mathrm{e}-66)$. C) Percentage of genes targeted by 2 or 3 of the transfected miRNAs appearing in the overlap of the three studies is much higher than the number observed in single studies. D) Left: Genes targeted by all three miRNAs show greater decrease in expression versus genes targeted by two or a single miRNA. Right: Genes with multiple miRNA binding sites displayed higher silencing level in comparison to genes with a single miRNA binding site. E) Percentage of miRNA target genes in all three, two, or single studies with increased expression in GBM in relation to normal brain (cortex) and stage 4 neuroblastoma compared to stage 1.

A

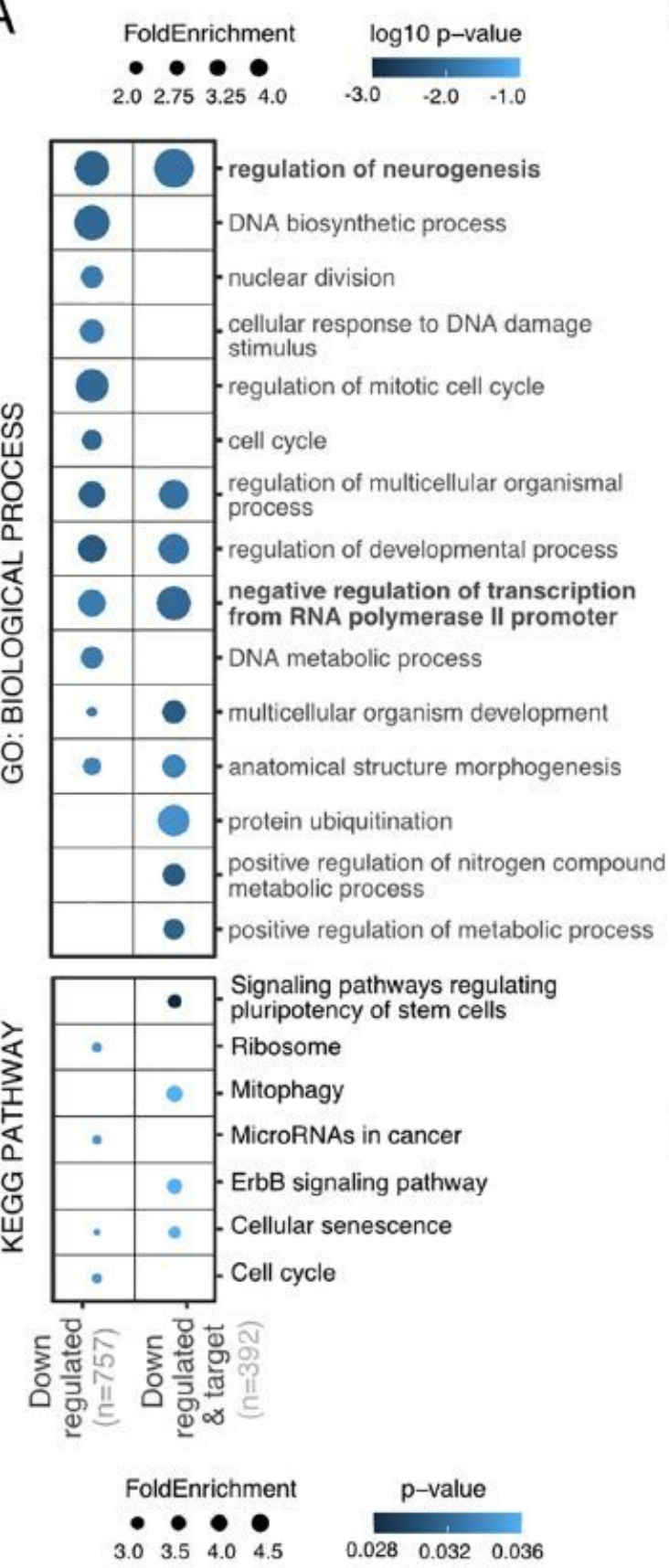

B

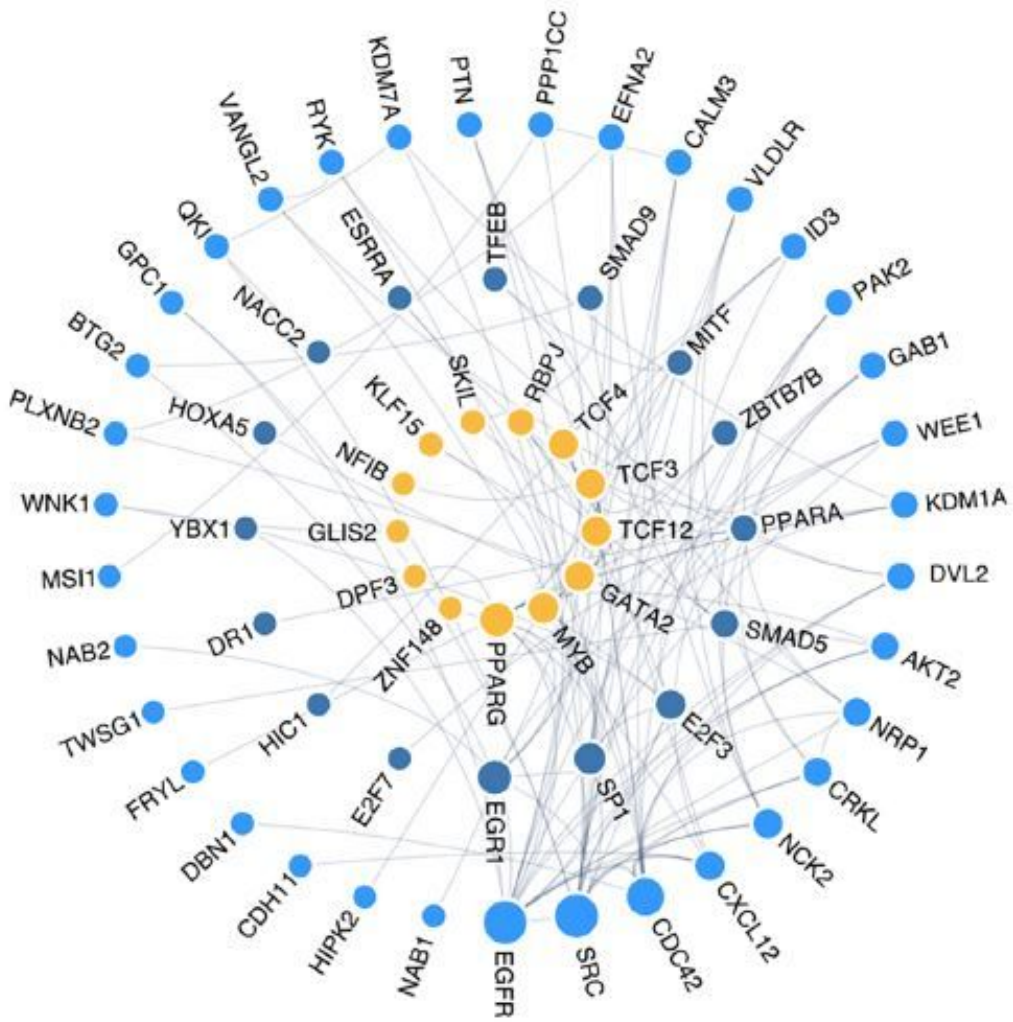

NERVOUS SYSTEM DEVELOPMENT

- TRANSCRIPTION FACTOR

BOTH

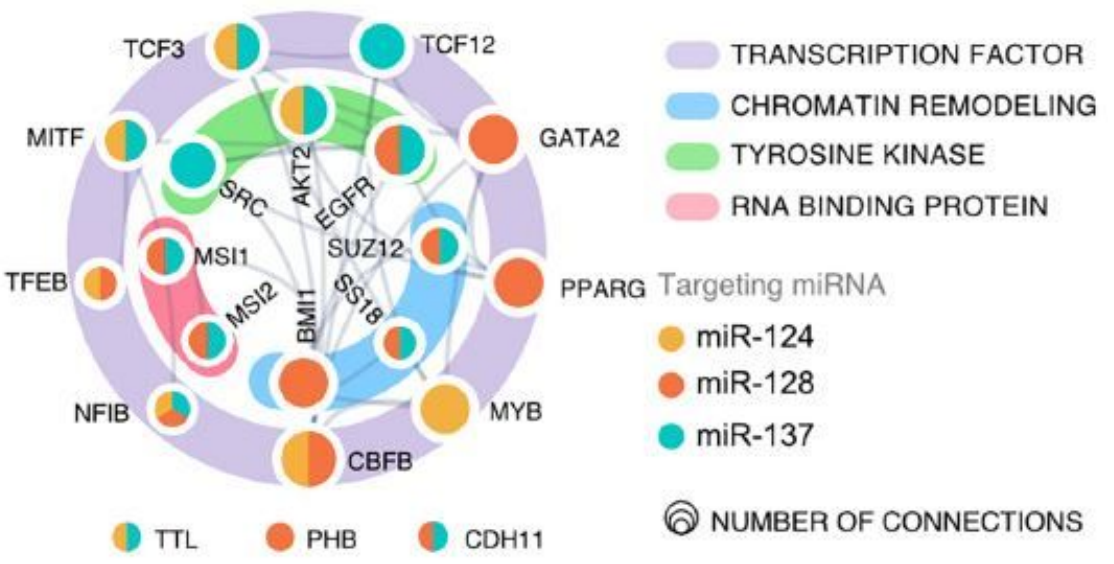


Gene ontology analysis of downregulated genes upon miRNA combo transfection. A) Enriched biological processes and KEGG pathways identified by PANTHER and ShinyGO $[39,41]$ associated with downregulated genes observed in at least two RNA-Seq analyses. B) Network showing detected targets of the transfected miRNAs appearing in at least two RNA-Seq studies implicated in nervous system development and transcription regulation according to STRING [44]. C) Oncogenes identified as targets of miR-124, miR-128 and miR-137 in the genomic analysis and their functions.

A

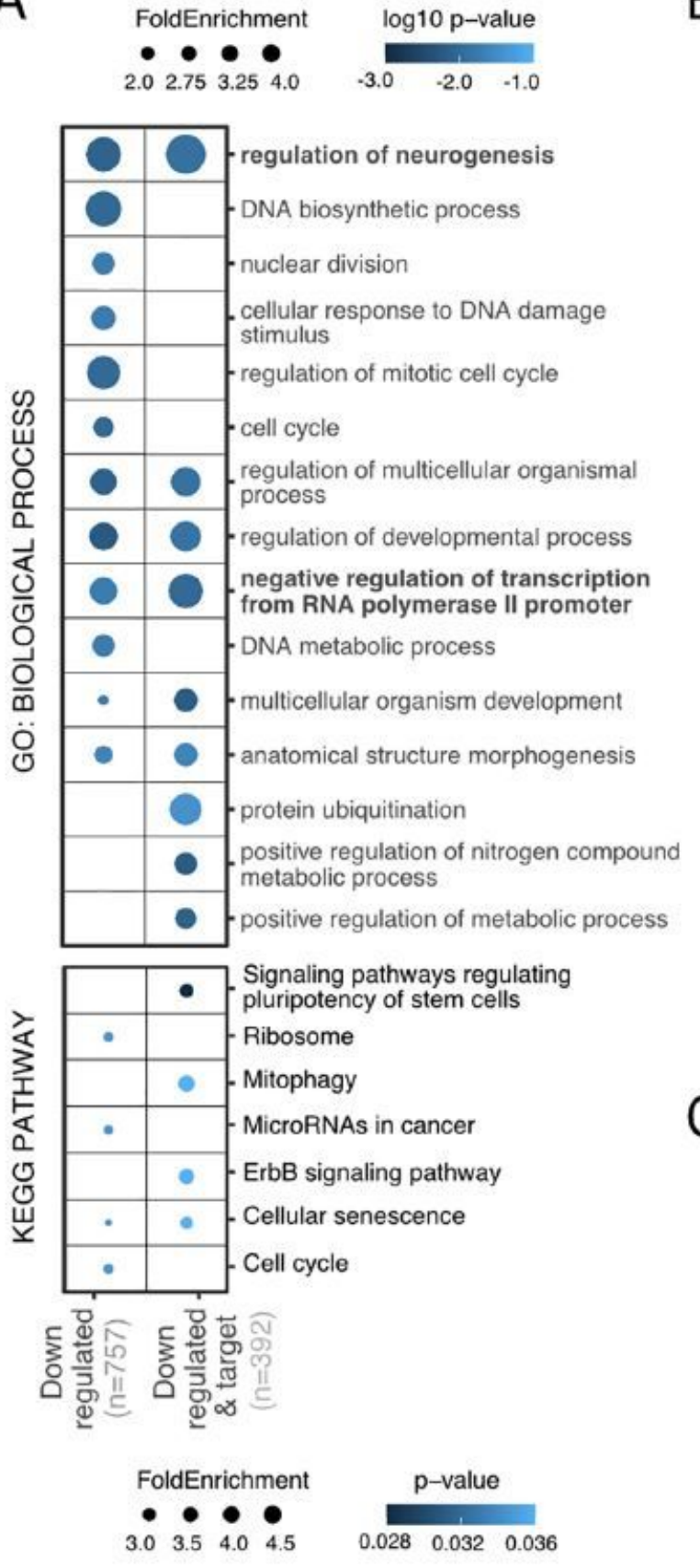

B

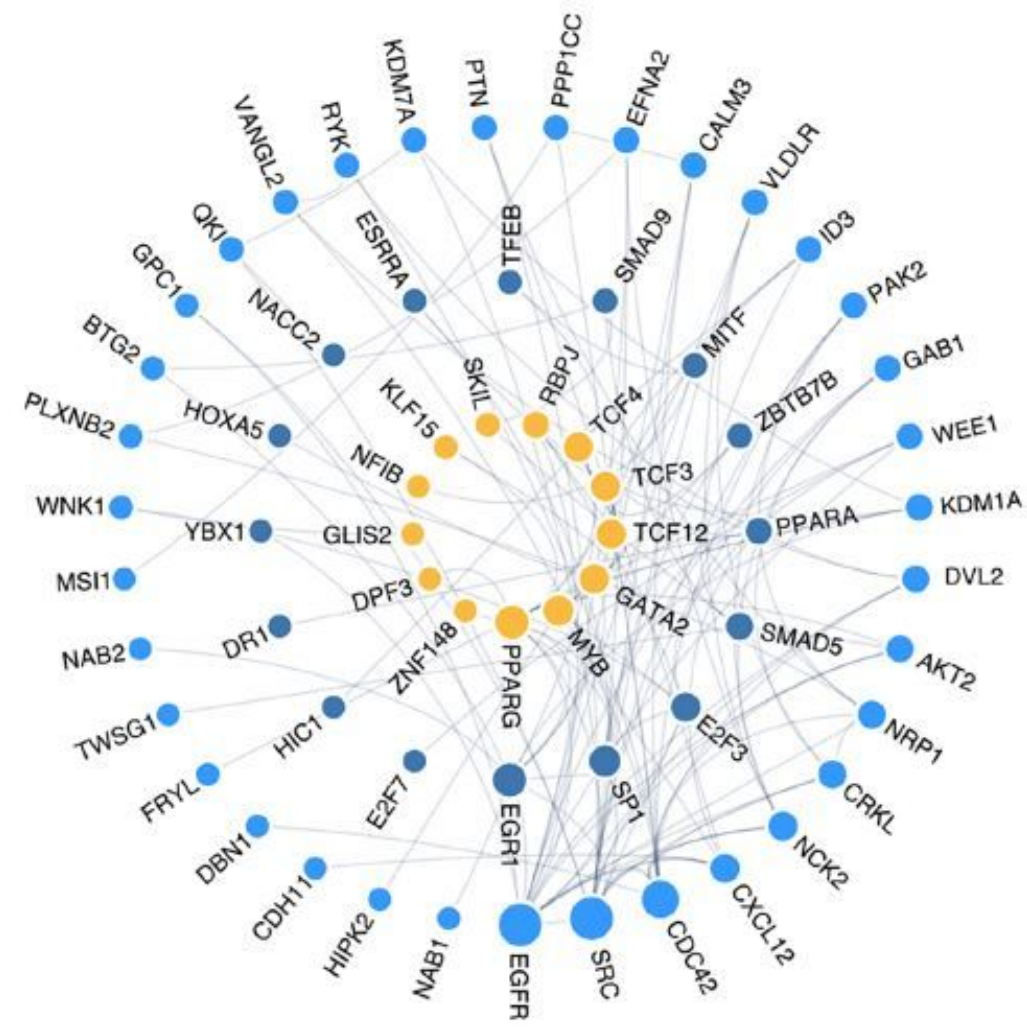

NERVOUS SYSTEM DEVELOPMENT

- TRANSCRIPTION FACTOR

BOTH

C

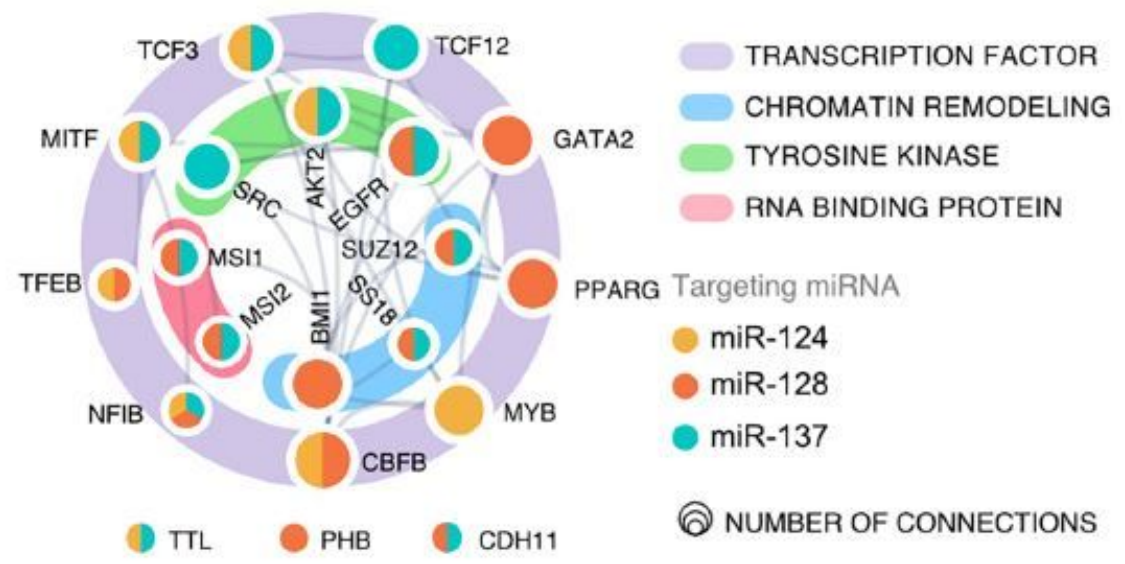

Figure 6

Gene ontology analysis of downregulated genes upon miRNA combo transfection. A) Enriched biological processes and KEGG pathways identified by PANTHER and ShinyGO $[39,41]$ associated with downregulated genes observed in at least two RNA-Seq analyses. B) Network showing detected targets of 
the transfected miRNAs appearing in at least two RNA-Seq studies implicated in nervous system development and transcription regulation according to STRING [44]. C) Oncogenes identified as targets of miR-124, miR-128 and miR-137 in the genomic analysis and their functions.

A

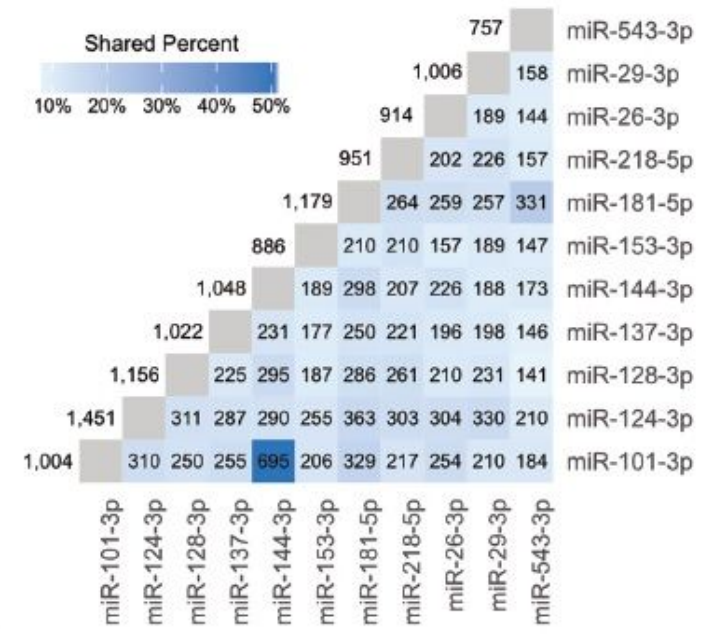

C

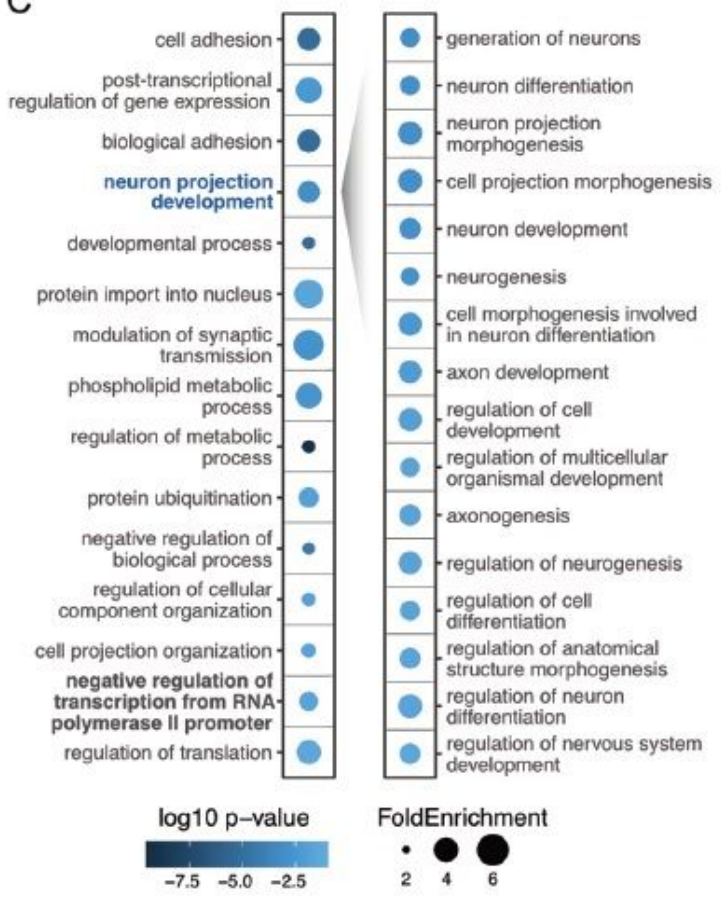

B

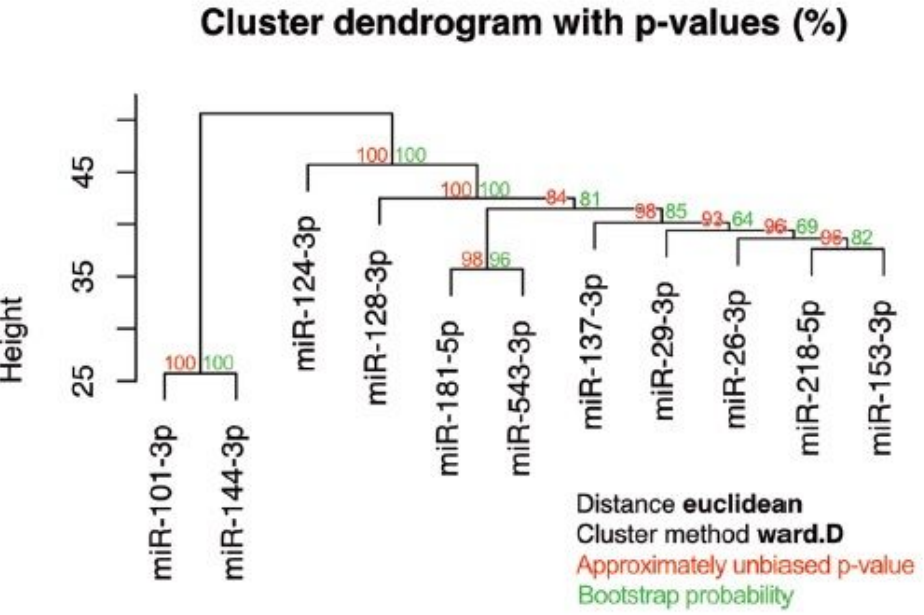

D

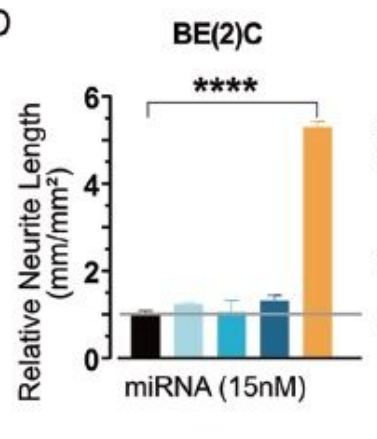

$\mathrm{BE}(2) \mathrm{C}$

U251

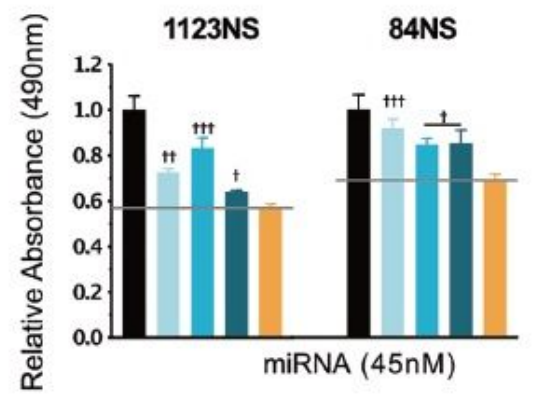

miRNActrl miR-101 miR-29
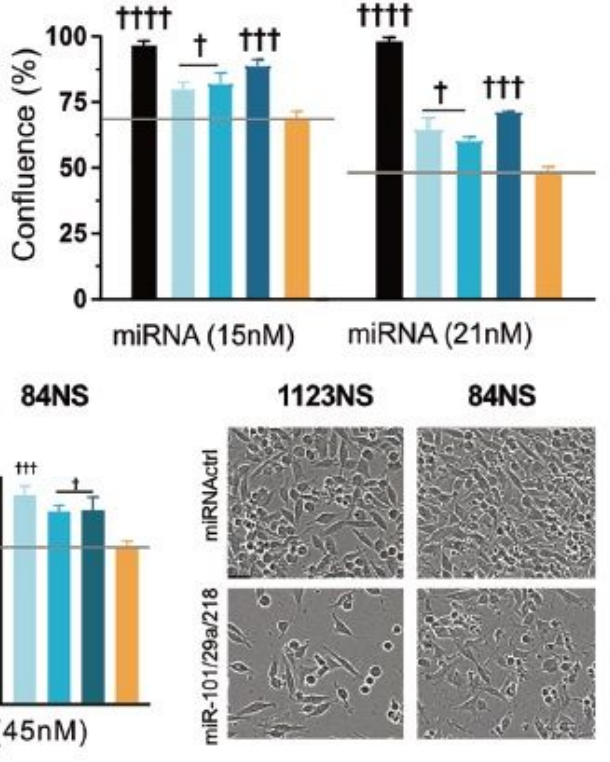

$\mathrm{miR}-218=\mathrm{miR}-101 / 29 \mathrm{a} / 218$

\section{Figure 7}

Associated tumor suppressor miRNAs offer other choices of combination treatment. A) Identified tumor suppressor miRNAs showing strong target overlap according to Targetscan predictions [46]. Numbers indicate overlapping targets and the percentage of overlap is indicated by shading. C) Gene Ontology analysis according to PANTHER [39] shows enriched biological processes for genes predicted to be targeted by at least 5 of the miRNAs listed in A. D) BE(2)C, U251, 1123NS and 84NS cells were transfected with the same molecular amount of single miRNA mimics (control, miR-101, miR-29, or miR- 
218) or combination of three miRNAs. First bar graph: Effect of miRNA transfection (single vs. combination) on $\mathrm{BE}(2) \mathrm{C}$ cell differentiation at 120 hours; neurite outgrowth was used as parameter of neuronal differentiation. Second, third and fourth bar graphs: Effect of miRNA transfection (single vs. combination) on cell proliferation at 120 hours. One-way ANOVA with Tukey test for multiple comparisons was used to analyze results of all experiments. p-values for comparisons against miRNA combination: $t p<0.05 ; \uparrow+\uparrow p<0.001 ;+\uparrow+t p<0.0001$.

A

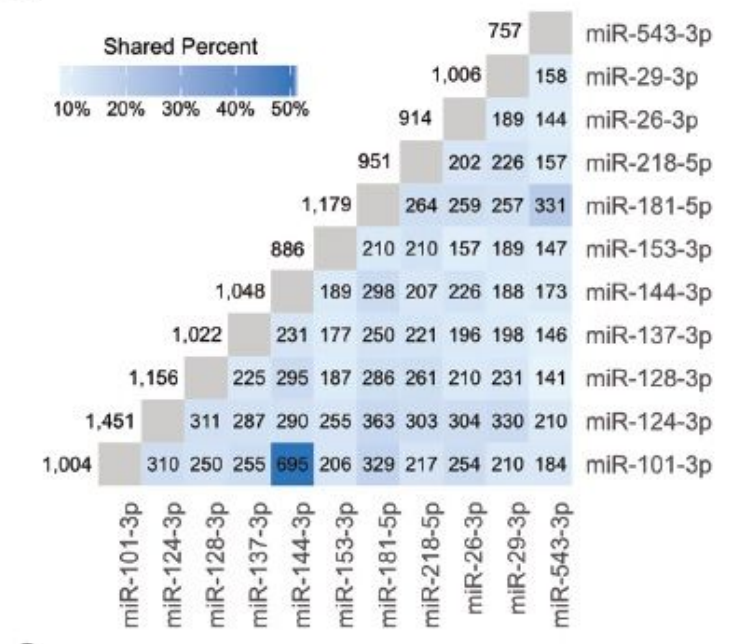

C

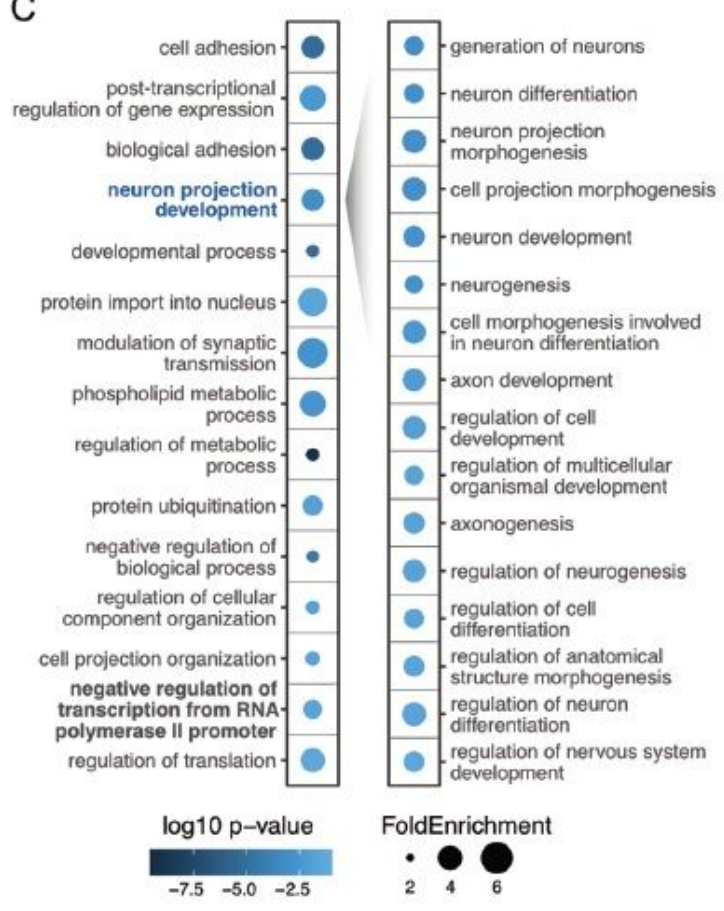

B
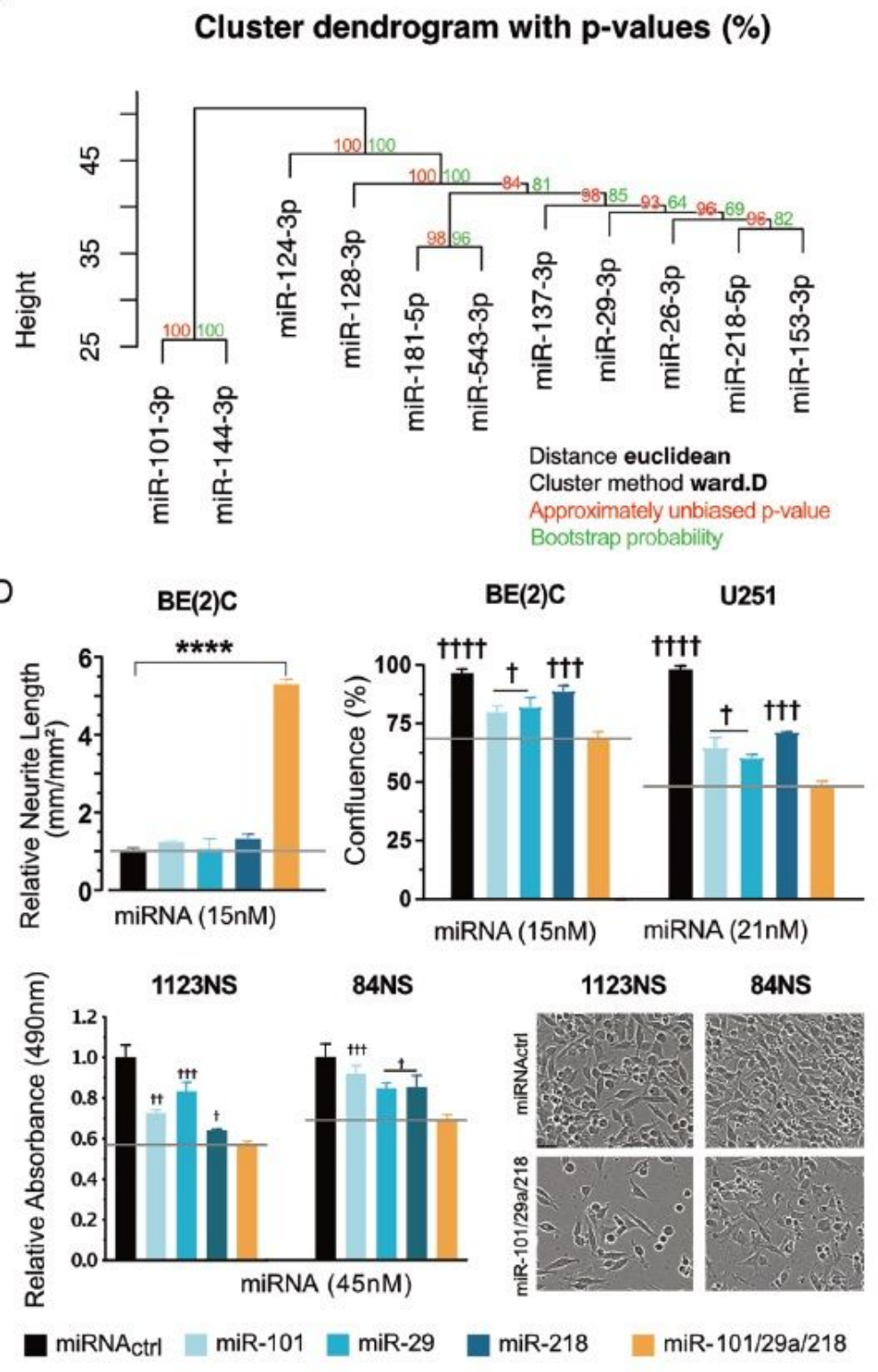

\section{Figure 7}

Associated tumor suppressor miRNAs offer other choices of combination treatment. A) Identified tumor suppressor miRNAs showing strong target overlap according to Targetscan predictions [46]. Numbers indicate overlapping targets and the percentage of overlap is indicated by shading. C) Gene Ontology 
analysis according to PANTHER [39] shows enriched biological processes for genes predicted to be targeted by at least 5 of the miRNAs listed in A. D) BE(2)C, U251, 1123NS and 84NS cells were

transfected with the same molecular amount of single miRNA mimics (control, miR-101, miR-29, or miR218) or combination of three miRNAs. First bar graph: Effect of miRNA transfection (single vs. combination) on $\mathrm{BE}(2) \mathrm{C}$ cell differentiation at 120 hours; neurite outgrowth was used as parameter of neuronal differentiation. Second, third and fourth bar graphs: Effect of miRNA transfection (single vs. combination) on cell proliferation at 120 hours. One-way ANOVA with Tukey test for multiple comparisons was used to analyze results of all experiments. p-values for comparisons against miRNA combination: $\uparrow \mathrm{p}<0.05 ;$ †††p $<0.001 ;$ ††††p $<0.0001$.

\section{Supplementary Files}

This is a list of supplementary files associated with this preprint. Click to download.

- sfigure1.pdf

- sfigure1.pdf

- sfigure2.pdf

- sfigure2.pdf

- sfigure3.pdf

- sfigure3.pdf

- sfigure4.pdf

- sfigure4.pdf

- sfigure5.pdf

- sfigure5.pdf

- table1.xlsx

- table1.xlsx

- table2.xIsx

- table2.xIsx

- table3.xlsx

- table3.xIsx

- table4.xIsx

- table4.xIsx

- table5.xIsx

- table5.xlsx

- table6.xlsx

- table6.xIsx 
- table7.xlsx

- table7.xlsx

- table1.xlsx

- table1.xlsx 